LCRL- 85944

PREPRINT

$$
\text { CONF. } 810948-3
$$

\title{
CHEMICAL PROPERTIES OF THE HEAVIER \\ ACTINIDES AND TRANSACTINIDES
}

\section{E. K. HULET}

\section{MASTER}

This review was prepared for publication in

the proceedings of the "Actinide 81 "

Conference

Asilomar, California

September 10-15, 1981

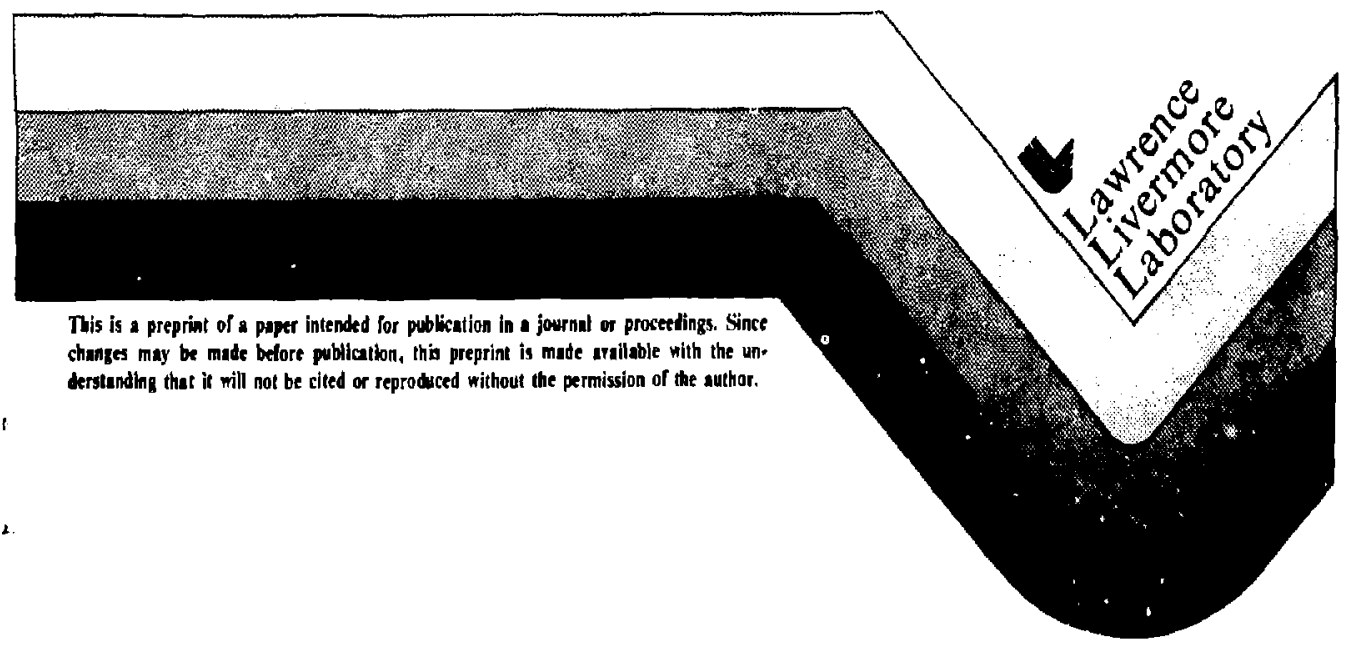




\section{CHEMICAL PROPERTIES OF THE \\ MEAVIER ACTINIDES AND TRANSACTIMIOES}

E. K. Hulet

University of California

Lawrence Livemore National Laboratory

P. 0. Box 808 , Livemore, California 94550

\section{ABSTRACT}

The chemical properties of each of the elenents 99 (Es) through 105 are reviewer and their properties correlated with the electronic structure expected for $5 \mathrm{f}$ and $6 \mathrm{~d}$ elements. A major feature of the heavier actinides, which differentiates them from the comparable lanthanides, is the increasing stability of the divalent oxidation state with increasing atomic number. The divalent oxidation state first becones observable in the anhydrous halides of cal ifornium and increases in stability through the series to nobelium, where this valency becomes predaminant in aqueous solution. In this range of element 5 , the II $\rightarrow$ III oxidation potentia] decreases from -1.5 to -1.5

volts. These cbservations lead to the conclusion that, in comparison with the analcgous $4 f$ electrons, the $5 f$ eiectrons in the latter part of the series are more tightly bound. Thus, there is a lowering of the $5 f$ energy levels with respect to the fermi level as the atomic number increases.

The netallic state of the heavier actinides has not been investigated except from the viewpoint of the relative volatility anong menbers of the series. In aqueous solutions, ions of these elements behave as "nomal" trivalent actinides and lanthanides (except for nobelium). Their ionic radii decrease with increasing nuclear charge which is moderated because of increased screening of the outer $6 \mathrm{~g}$ electrons by the $5 \mathrm{f}$ electrons. These relative ionic radii have been obtained from comparisons of the elution position in chronatographic separations.

The actinide series of elements is completed with the element lawrencium (Lr) in which the electronic configuration is $5 f^{147} \mathrm{~s}^{2} 7 \mathrm{p}$. From Mendeleer's periodicity and Dirac-Fock calculations, the next group of elements is expected to be a d-transition series corresponding to the elements Hf through Hg. The chemical properties of elements 104 and 105 only have been studied and they indeed appear to show the properties expected of eka-Hf and eka-Ta. However, their nuclear lifetimes are so short and so few atoms can be produced that a rich variety of cherrical infomation is probably unobtainable.

\section{KEYHORDS}

Review, solution chemistry, atomic properties, actinide compounds, metallic properties, separations. 


\section{INTRODUCTION}

The detailed chemistry of the heavier actinides has only become discernable within the past 12-14 years when berkelium, californium, and einsteinium first became available in appreciable quantities. Micro- to milligram quantities of these elements were necessary for service as target fsotopes in producing tracer amounts of even heavier actinides by charged particle bombardments. In addition, these quantities pemitted progress in understanding the chemical properties of the transcurjum elements (BK-Es) beyond that gathered from tracer-scale experiments. However, with each step in atomic number above that of Es (element 99), ye know less and less of each element's chemistry because of the increasingly shorter lifetimes of the nuclides and because of the difficulties in synthesizing sufficient numbers of atoms.

Because of the nuclear instabilities of these man-made elements, the range of atomic and chemical properties that are accessible to experimental study are indeed limited in comparison with the vastly wider spectrum of infomation obtainable from the naturally occurring elements. Among the basic chemical properties of the heavier actinides which have been invescigated are the behavior of these ions in solution which includes separation chemistries, complex-ion fomation, oxidation-reduction reactions, el ectrochenistry, hydration, and absorbtion spectre. Our experimentally derived knowledge becones scantier for other chemical forms and states of these elements as, for example, the organometallic compounds and the elemental and solid states. Atomic and physical-chemical properties are almost entirely unknown for the elements heavier than einsteinium, except where derived by theoretical extrapolations. Nevertheless, all of the small bits of knowledge so far obtained allow us to piece together a rather clear picture of the basis chemistry of these elements.

A condensed scheme that summarizes the valence states and numbers of $5 f$ electrons in each state is shown for the actinides in Fig. 1. Elements within the first half of the series are stable in the IV, $V$, and VI valence states, while the divalent state is almost unknown in this group. However, one of the major features uncovered in the investigations of the heavier actinides was a finding of increasing stability of the divalent state with progressive increases in atomic number. This trend, like the high and stable valences in the lighter nembers of the series, sets the actinides apart from the comparable fanthanide series and can be generally interpreted on the basis of subtle changes in electronic structure. The most important change accurring with incieasing $Z$ is a marked lowering of the $5 f$ energy levels with respect to the Ferni level and a widening separation between the $5 f$ ground states and the first excited states in the 60 or $7 p$ levels. Thus, removing an outer $5 f$ valence electron becomes increasingly difficult untif divalency predominates in the next to last actinide element in the series. These and other gerteral features of the chenistry of the heavier actinides are surmarized after the review of lawrencium.

\section{EINSTEINIUN}

\section{Production}

The isotopes $253 \mathrm{Es}$ and $254 \mathrm{gEs}$, with half 1 ives of 20.5 and 275.7 days, respectively, can be produced in high-flux nuclear reactors in sufficient 

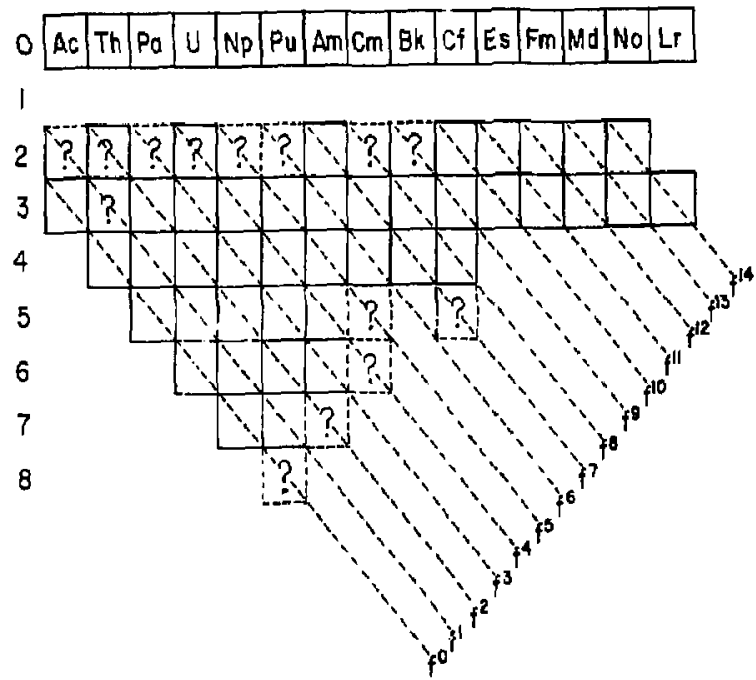

Fig. 1. Schematic of actinide oxidation states and associated 5 felectronic structure.

guantities for chemical investigations. Starting with neutron capture by $238 \mathrm{U}$, the production of $253 \mathrm{Es}$ proceeds through a long chain of further captures and beta decays by intemediate nuclides during long neutron irradiations. The yearly production of $253 \mathrm{Es}$ from 1962 onward is shown in Fig. 2 . The production of $253_{\mathrm{Es}}$ has by now leveled of $f$ at a rate of about two milligrans per year while the amounts af 2549Es and $255 \mathrm{Es}$ are necessarily limited by the fission destruction of $254_{E s}$ to about 0.3 and 0.06 percent of the 253 Es quantities, respectively(1). Prior to 1969 , einsteinium and the other transplutonium elements were produced by the individual National Labor:t:ories but an overall U.S. production program, maintained at the Oak Rioge National Laboratory by the U.S. Department of Energy, has since superseded those individual efforts.

\section{Atomic Properties}

The electronic configurations of einsteinium in neutral and singly ionized gaseous atoms have been detemined from enission spectra taken with electrodeless discharge lamps containing EsI3. Although the first emlssion spectrum of einsteiniun revealed only 9 lines(2), the most recent exposures using the 10-m spectrograph at the Argonne Hational Laboratory are expected to show some 20,000 lines $(3)$. Unfortunately, the measurenents on these photographic plates are incomplete and the electronic configurations given in Table 3 are based on term assignments to a portion of the 290 lines obseryed earlier by Worden et al. (4). It should be noted that not all of the lowest energy electronic conflgurations have been observed yet. Brewer 


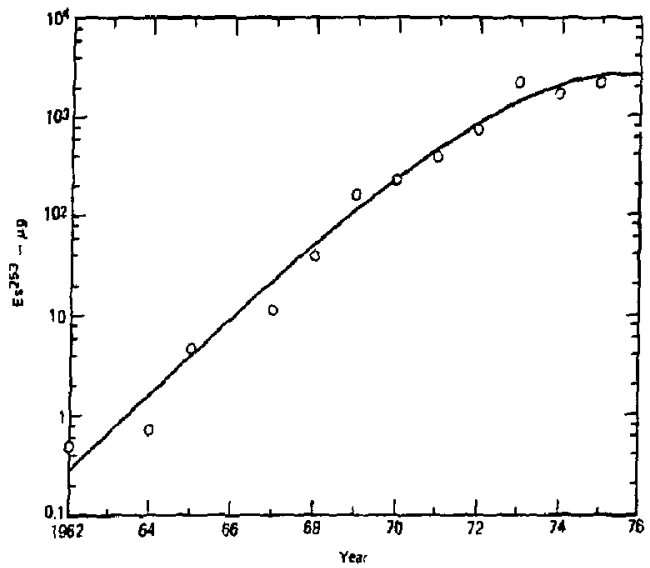

Fig. 2. Yearly production of $253 \mathrm{ts}$ in the United States.

has tabulated his estinated energies of the lowest level of the lowest spectroscopic term for each electron configuration $(5,6)$. For the singly ionized free atom, it is apparent from his estimates that the fios ${ }^{2}$, ${ }^{12}$ and fll $l_{d}$ should be lower in energy than the first excited level $f$ it $p$ observed by Worden and others (4). Other atomic properties from atomic bean and $x$-ray measurements are listed in Table 1.

\section{Metallic State}

The high specific radioactivity of einsteinium has greatly limited the in. vestigations of the metal. Of the two attempts to prepare the metal and determine its structure, the successful method employed electron diffraction rather than $x$-ray diffraction. The latter was largely inconclusive because of degradation of the metal's crystallinity caused by self-irradiation. The electron diffraction lines from eleven samples were indexed on the basis of a face-centered cubic structure with $a_{0}=0.575+0.001 \mathrm{~nm}(11)$. This foc form of einsteinium metal is believed to be divalent because it has the same lattice parameter as reported for the divalent form of californium metal.

A melting point for the metal was also noted wile heating the samples in the electron microscope used for the diffraction measurements. Micro puddles of the fotal formed during the heating and, after calibrating with metals of known melting points, a temperature of $860 \pm 50^{\circ} \mathrm{C}$ was established as the melting point of einsteinium metal.

Further evidence for divalency in Es metal has cone from studies comparing the condensation temperatures of elemental lanthanides and actinides in themochromatographic columns(12). The trivalent metals SC, La, and BK were 
TABLE 1 Aiomic Properties of Einsteinium (253 Es)

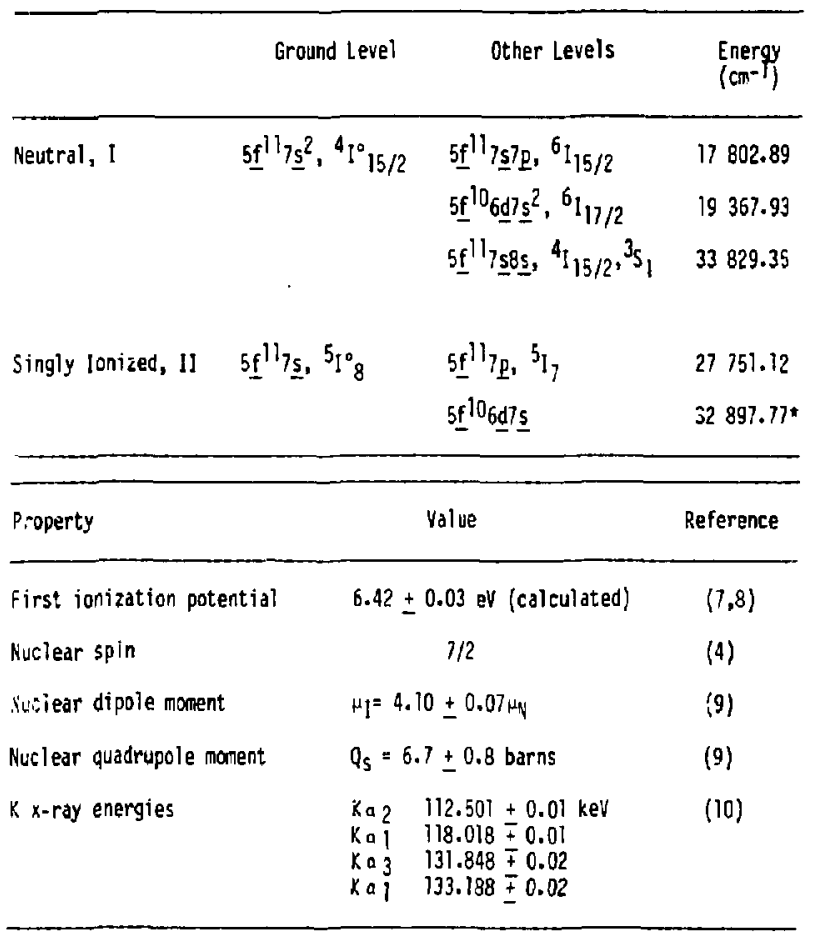

- May not be the lowest level of this configuration.

not volatilized at the initial temperature of $1425^{\circ} \mathrm{K}$, whereas the metals of $\mathrm{Yb}, \mathrm{Es}, \mathrm{Fm}$, and $\mathrm{Md}$ were vaporized and later condensed at the same temperature $\left(-700^{\circ} \mathrm{K}\right)$. The behavior of divalent $\mathrm{Eu}, \mathrm{Sm}$, and Ca metals was intermediate between thos? extremes. Since volatilities are correlated with promotional energies and the number and energy of the valence bonds, the more volatile actinides are associated with the divalent metals. The estimates of Nugent et al. (13) for the enthalpy of sublimation of lanthanide and actinide metals cTosely agree with the relative volatilities found in the thermochromatographic study reported above. Furthemore, Ward and colleagues (14) have recently completed detailed analyses of the cohesive energy of the actinide metals (entropies and heats of sublimation), in which they also fndicate that einsteinium is a divalent metal.

The thermal conductivity of einsteinium has been estimated to be $10 \mathrm{H} \mathrm{m}^{-1}$ $k=1$ at $300^{\circ} \mathrm{K}(15)$. 


\section{Compounds}

Only a few simple compounds of einsteinium have been prepared and structuraliy identified. Aside from self-destruction of the crystal structures, there is a rapid in-growth of the a-daughter $249_{B K}$; the $L, M$, and $N$ X-rays, emitted following a-decay blacken the $x$-ray film used in Debye-Scherrer cameras within 10 to 20 minutes with microgran samples of $253 \mathrm{Es}$ or $2549_{\mathrm{E}} \mathrm{s}$. A synchrotron radiation source may be the only way of oventhelming this sample background source of radiation with sufficient intensity of monochromat ic radiation to permit diffraction measurements.

The known compounds of einsteinium dre listed in Table 2 together with the rather sparse infomation detailing their properties. Oivalent compounds were not identified by their ciystal structure, but by adsorption spectra of their halides, taken with crystallites or of samples first melted and then quenched. These spectra show a sharp difference in the $f$-f absorption bands

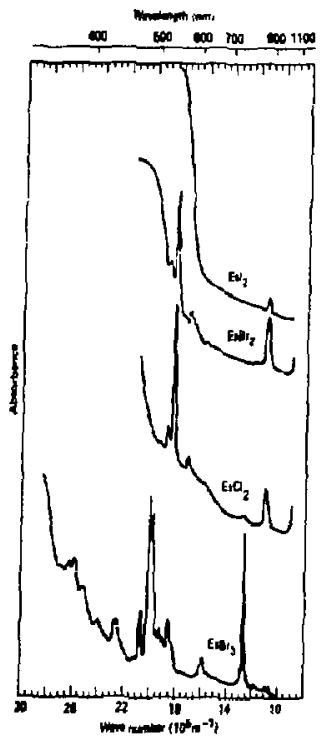
wen compared to the corresponding spectra of the trivalent halides (Fig. 3). He emphasize that the apparent stability of the divalent oxidation state in ein. steinium was not realized until a decade ago and that this feature in the heavier actinides clearly sets this series of el ements apart from the later elements in the $4 f$ series.

Fig. 3. Absorption spect ra of the divalent einsteinium halides and trivalent EsBrz. Reprinted with the permission of the $J$. Phys. Collo. (Ref. 25).

Electron paramagnetic-resonance spectra of divalent einsteinium have been recorded in single-crystal hosts of $\mathrm{CaF}_{2}(16), \mathrm{BaF}_{2}$, and $\mathrm{SrF}_{2}(17)$. Reduction of $\mathrm{Es}^{3+}$ to $\mathrm{Es}^{2+}$ was spontaneous from electron displacement caused by the a-radiation. A $5 f$ configuration with a ground state close to the ${ }^{2} I_{15 / 2}$ level, but with a small admixture of the ${ }^{2} K_{15} / 2$, was found, which indicates the cubic crystal-field only sifghtly perturbs the inner $5 f$ orbitals.

A possible tetravalent compound $\mathrm{EsF}_{4}$ may also exist, as judged by comparing the volatility of an einsteinium fluoride with $\mathrm{PuF}_{4}, \mathrm{AmF}_{4}, \mathrm{CmF}_{4}, \mathrm{BKF}_{4}$, and $\mathrm{CfF}_{4}(18)$. The f-f electronic spectrum of the $\mathrm{Es}^{4+}$ free lon has been calculated by Varga añd coworkers(19). Nugent et al.(20) and Lebedev(21) estimated a III $\rightarrow$ IV oxidation potential of $-4 . \overline{6} \sqrt{ }$ wich Nugent thought might allow the synthes is of the compound $\mathrm{CS}_{3} \mathrm{EsF}_{7}$. 
TABLE 2 Simple Compounds of Di-aldy irivolent Einsteiniun Charac-

\begin{tabular}{|c|c|c|c|c|c|c|c|c|}
\hline & Compound & $\begin{array}{c}\text { Structural } \\
\text { Type* }\end{array}$ & $a_{0}$ & $\begin{array}{c}\text { Latcice } P \\
\text { (a.bo, } \\
b_{0}=c_{0}\end{array}$ & $\begin{array}{c}\text { arameters } \\
\left.\text { nm; } \operatorname{Bin}_{\mathrm{in}_{0}}^{\circ}{ }^{\circ}\right)\end{array}$ & $\beta$ & $\begin{array}{c}\text { Major Absorption } \\
\text { Bapds } \\
\left(10^{5^{d s}}-1\right)\end{array}$ & Reference \\
\hline & $\mathrm{Es}_{2} \mathrm{O}_{3}$ & $\mathrm{Mn}_{2} \mathrm{O}_{3}$-bce & $1.0766 \pm 0.0006$ & & & & --- & 22 \\
\hline & $\mathrm{EsCl}_{3}$ & $u C l_{3}-h_{e x}$ & $0.740 \pm 0.002$ & & $0.407 \pm 0.002$ & & (see Ref 23) & 23.24 \\
\hline & $\mathrm{EsCl}_{2}$ & $-\cdots$ & & & & & $11.7,18.5,24.5$ & 25,26 \\
\hline & Esoc 1 & PbFC1-tetra & $0.3948+0.0004$ & & $0.6702+0.0019$ & & $m$ & 23,24 \\
\hline & $\mathrm{EsBr}_{3}$ & $\mathrm{AlCl}_{3 \text {-mono }}$ & $0.727 \pm 0.002$ & $1.259 \pm 0.003$ & $0.681 \pm 0.002$ & $110.8 \pm .2$ & $12 \cdot 6,19.8$ & 27 \\
\hline & EsBr2 & --- & & & & & $11.2,18.3$ & 25 \\
\hline & EsOBr & --- & & & & & (no published data) & 23 \\
\hline & $\mathrm{EsI}_{3}$ & $\mathrm{BiI}_{3}$-hex & 0.753 & & 2.084 & & (see Ref 23) & 23,28 \\
\hline & $\mathrm{EsI}_{2}$ & $\ldots$ & & & & & $11.2,18.5$ & 25 \\
\hline & EsOI & -- & & & & & (no published data) & 23 \\
\hline & $\mathrm{ESF}_{3}$ & -- & & & & & $13.2,20.3$ & 23 \\
\hline
\end{tabular}

- bcc = body-centered cubic

hex = hexagonal

tetra = tetragonal 


\section{Separation and Purification}

The chemical recovery of einsteinium (and $\mathrm{BK}$, Cf, and $\mathrm{Fm}$ ) after irradiation is perioned remotely in large shielded cells. Details of the chemical separation processes used in the Inited States and by the Soviets at the Kurcilatov Institute of Atomin Energy have been reviewed by Hulęt and Bodé (29) and by Kosyakov and coworkers(30), respectively. Nearly all of tile separantion steps used in these large-scale processes were developed earlier for applications in laboratory separations, but extensive modifications were were required to adapt then to the special and nearly al ways aciverse condi. tions encountered in remote operations with very high levels of radioactivity present. These separation processes are unlikely to be scaled up further as, for instance, for the recovery of transplutonium elements during the reprocessing of fuel from power reactors. This is Targely because they were born in the laboratory were corrosive chemicals could be easily contained in glass apparatus and where the chemist could oversee the difficult chromatographic separations.

Purification of einsteiniun requires two difficult separations: 1) from lanthanide fission products and 2) from adjacent actinides. The main difficulty arises from the great similarity in the chemical properties of their trivalent ions. Fortunately, the contraction in size of the aqueous ions with increasing atomic number can be exploited with complexing ligands to offer slight variations in complex strengths between members of either series of $f$ elements. Chromatographic mathods then exploit these smali chenical differences many times over to give useful separation factors for the tripositive el ements.

Separation of einsteinium from the lanthanides is usually accomplished by elution with either $13 \mathrm{M} \mathrm{HCl}$ or 20 vol \% ethanol saturated with $\mathrm{HCl}$ from all ion-exchange column containing a strongly acidic cation exchange resin(31). Einsteinium and the other actinides are rapidly eluted in a band while the trivalent lanthanides are retained and eluted somewhat later. The purification of einsteinium from many milligrans of lanthanides necessitates an inion-exchange procedure using $10 \mathrm{M} \mathrm{LiCl}$ as an eluant (32). With this elution method, Cf, Es, and Fm are separated from all lantharides, Pu, Am, and Com with separation factors ranging from 4 to 23.

The intragroup separation of einsteinium from adjacent actinides can be performed by either of two chromatographic methods. In the ion-exchange method :he trivalent actinides are eluted with a complexing agent such as 2-hydroxy. 2-methyipropanoic acid (a-hydroxyisobutyric acid or aHIB) from a heated column of cation exchange resin containing a strongly acidic, highly crosslinked resin(33). Such columns are often run at pressures up to $17.2 \mathrm{MPa}$ to force the eluant through the very fine particles of ion-exchange resin $(3 i)$. The second method employs extraction chromatography in wich the extractants, either bis(2-ethylhexyl) phosphoric acid (HDEHP) or 2-ethylhexylphenyl phosphonic acid (HEHPP), are absorbed on an inert support material(29). An eluant of approximately 0.3 to $0.4 \mathrm{M} \mathrm{HCl}$ or $\mathrm{HMO}_{3}$ provides distribution coefficients appropriate for Es-Fm separations. Table 3 sumparizes the separation factors (ratio of distribution coefficients) obtainable by each of these mothods. Clearly, the purification of Cf from Es is the poorest; hence, the cation exchange method is preferred because of the larger separation factor. The major difference between the two methods of chromatographic separation lies in a reversal of the elution sequence with atomic number. 
TABLE 3 Separation Factors $\left(S=K_{d}(\tau) / K_{d}(z+1)\right.$ for Es/Fm and Cf/ES Obtained with Acidic Extractants and by Cation-exchange. Average Values from Rcf. $29, P .11$, and Ref. 35 are Lišted

\begin{tabular}{|c|c|c|c|c|}
\hline \multirow[t]{2}{*}{ Elements } & $\begin{array}{c}\text { aHIB } \\
\left(87^{\circ} \mathrm{C}\right) \\
\end{array}$ & \multicolumn{2}{|c|}{$\begin{array}{l}\text { HDEHP } \\
\left(60^{\circ} \mathrm{C}\right)\end{array}$} & \multirow{2}{*}{$\begin{array}{c}\text { HEHDP } \\
\left(25^{\circ} \mathrm{C}\right) \\
\mathrm{HC} \\
\mathrm{S} \\
\end{array}$} \\
\hline & & $\begin{array}{c}(H[1) \\
5\end{array}$ & $\begin{array}{c}\left(\mathrm{HNO}_{3}\right) \\
5\end{array}$ & \\
\hline \multirow[t]{2}{*}{$C f$} & & & & \\
\hline & 1.5 & 0.99 & 1.02 & 1.3 \\
\hline Es & 1.7 & 2.04 & 2.20 & 2.5 \\
\hline
\end{tabular}

\section{Solution Chemistry}

Irivalent ions. Across the actinide series from $P u$ to $L r$, the solution properties of the $\mathrm{An}^{3+}$ ion vary only slowly and in a regular manner. Thus, much of the behavior described in prior chapters for trivalent actinits ions can be safrily extrapolated to estimate that of $\mathrm{Es}^{3+}$. Bonding with ligands is almost entirely attributed to electrostatic force:; but with some second-order contribution from covalent sharing of electrons due to the relatively large radial extension of the of orbitals. The ionic radius of is ${ }^{3+}$ ias been calculate from the six-coordinated sesquioxide to give d vaitue of $0.0928 \mathrm{~nm}(22)$, or about i pro smaller ran the radius of $\mathrm{Cf}^{3+}$. Eiristeiniun is stable only as the trivalent $10 n$ in aqueous solution.

A number of measurements of the absorption spectrum of $253 \mathrm{Es}^{3+}$ have been made over the energy range of 9430 to $34,000 \mathrm{~cm}^{-1}(36-39)$. The band structure (12 peaks) observed could be reasonably well fitted in both energy and intensity by assuming $E^{3+}$ behaved as a free ion and that the $f-f$ transition arose from eigenstates wich were strongly mixed because of coupling that is intemediate between $L-s$ and $j-j(37-40\}$. These assumptions fo!lok closely those used in fitting calculated Terels to identified absorption bands in preceeding members of the actinide (and lanthanide) series.

Studies of the complex-ion chemistry of $\mathrm{Es}^{3+}$ have been made in conjunction with measurements of the stability constants of other trivalent actinides. A summary of the known stability constants for einsteinjum complexes is shown in Table 4 . Figure 4 is illustrative of the trend of greater complex formation with increasing atomic number for the trivalent actinides. The step-wise increase in $\beta_{3}$ between $C_{m}$ and $B k$, often seen as part of the tetrad effect, is related to che first pairing of a $5 f$ electron at Bk after half filling the $5 f$ shell in Cm. With the possible exception of the two lower thiocyanate complexes, the chloride is the only outer-sphere compiex in which waters of hydration lie between the ligand and einsteinium ion. The remaining complexes are believed to be inner-sphere as inferred from the increase of a given stability constant with an increase in atomic number and from the enthalpy and entropy of fomation of the complex. 
TABLE 4 The Stability Constants of $\mathrm{Es}^{3+}$ Complexes

\begin{tabular}{|c|c|c|c|c|}
\hline \multirow[t]{2}{*}{ Complex } & \multicolumn{3}{|c|}{ Stability Consiant } & \multirow[t]{2}{*}{ Reference } \\
\hline & $\log \beta_{1}$ & $\log \beta_{2}$ & $\log \beta_{3}$ & \\
\hline$E s C\}^{2+}$ & -0.18 & & & (41) \\
\hline $\mathrm{ESOH}^{2+}$ & 8.86 & & & (42) \\
\hline $\mathrm{Es}\left(\mathrm{SO}_{4}\right)_{\pi}^{3-2 \mathrm{n}}$ & -2.19 & -4.3 & -4.93 & (43) \\
\hline$\varepsilon s(S C N)_{n}^{3-n}$ & 0.559 & $-3,4$ & 0.468 & (44) \\
\hline EsHCit2- & 10.6 & & 1 & $(45)$ \\
\hline$E s(\text { Cit })_{2}^{3-}$ & 12.1 & & 1 & \\
\hline$E s(H I B)^{2+}$ & 4.29 & & & \\
\hline Es(tartrate) ${ }^{+}$ & 5.86 & & \} & $(46)$ \\
\hline Es(malate $)^{+}$ & 3.06 & & & \\
\hline ESDETPA2- & 22.62 & & & \\
\hline ESDACTA- & 19.43 & & & (47) \\
\hline ESEDTA & 19.11 & & & \\
\hline
\end{tabular}

Cit $=$ citrate ion

oHIB = 2-hydroxy-2-methylpropanoate ion

DEPTA = diethylenetriaminepentacetate ion

DACTA $=1,2$-diaminecyclohexa netetraacetate ion

EDTA = ethylenedi aminetetraccetate ion 


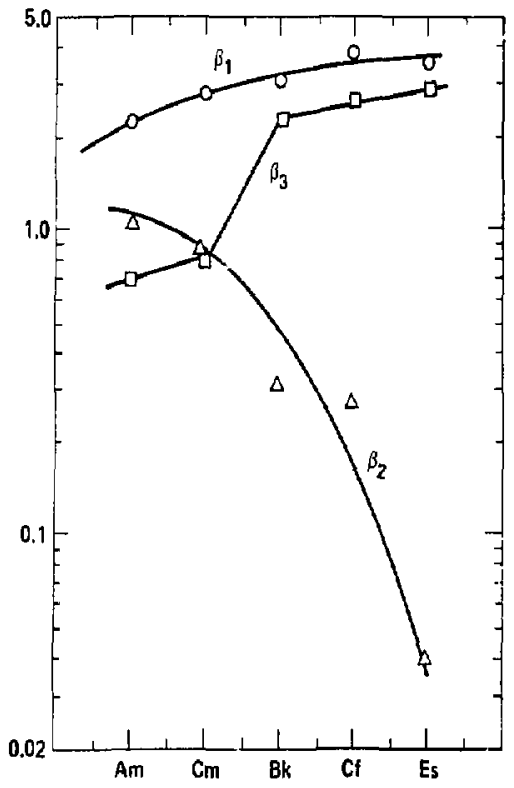

Fig. 4. First three stability constants of the actinide (III) thiocyanate complexes as a function of atomic number. Redrawn from the dita of Hamon and Peterson (44).

Hydrated radii and hydration numbers for the $\mathrm{An}^{3+}$ ions have recently been derived from miglation rates in an electric field and from Stokes' Law(48). The hydrated ions of einsteinium and fermium are the largest in the series $\mathrm{Am}^{3+}$ to $\mathrm{Md}^{3+}$; the hydrated radius of einsteinium is $0.492 \mathrm{~nm}$ which would allow 16.6 molecules of water in the total hydration sphere. Several parameters of thermodynamic interest have been measured or estimated; e.g. the molar activity coefficient of $\mathrm{Es}^{3+}$ in $\mathrm{NaNO}_{3}$ solution(49) and the free energy, enthalpy, and fntropy of formation of $t_{s}{ }^{3+}$ in aqueous solution(2l).

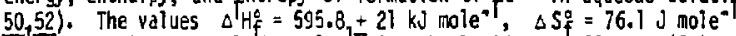

$\bar{K}^{-1}$. and $\Delta F_{f}^{b}=573 \pm i 7 \mathrm{~kJ}$ mole $e^{-1}$ given by David and colleagues $(50)$

were obtained froin an entropy prescription and the standard reduction potential, $111 \rightarrow 0$, described in the following paragraph.

For the purpose of measuring the electropotential, reduction of the trivaient einsteinium ion to the metal ( $\mathrm{Hg}$ amalgam) has been perfomed by polarographic methods. A single half-wave representing tine [II $\rightarrow 0$ reduction potential was observad(53). The potential founo for the combined reactions of reduction and amalgamation was $-1.460+0.005 \%$. After correcting for the amalgamation energy by an enpirical method suggested by Nugent (52), the stondard potential derived was $-1.98 \vee$ re' ative to the standard hydrogen 
potential. Because the amolgamation energy represents a large correction, caution should be exercised in using the stendard potential in themodynanic calculations.

Qivalent ions. The divalent state is of major importance and has attractad the incerest of many experimenters since 1967 when the appreciable stability of this state was first recognized in the actinides. The III -11 reduction potential of einsteinium was first estimated to be $.1 .6 \mathrm{~V}$ from the lowest energy electron-transfer band(55). A later estimate of -1.21 was obtained for chloroaluninate melts $(56)$ as well as another estimate of the standard potential of $+1.18 V(54)$. Mikheev and coworkers identified Es(11) from the the cocrystallization of einsteinium tracer with $5 \mathrm{mCl}_{2}$ in an ethanol solu. tion(57). Einsteinium was only parifially reduced to the (II) state by $5 \mathrm{Cl}_{2}$. wich allowed them to conclude that the standard reduction potential of $\mathrm{Es}^{3+}$ was close to that of $\mathrm{Sm}^{3+}$, or $-1.55+0.05 \mathrm{~V}(58)$. An ionic radius of $0.105 \mathrm{~nm}$ was estimated frot the radius of maximum electron density obtained in Hartree-Fock calculations, which was then corrected to obtain the crystalline radius by an empirical proportionality constant (59).

\section{FEN ATOH CHEMISTRY}

Beginning with femium and witn each advancement in atomic number beyond, the amounts of these rare elenents that can be made avallable for chemicai research are measured in atoms rather than fractions of a gram. Heighable quantities cannot be synthesized and we speak of "atom chemistry" and even "one-atom-at-tjne chemistry" for the heaviest actinide and transactinides. These res]ities are illustrated in Table 5 , which aiso points to a second grave obstacle to chemical research with the elements listed, namely, the sharply decreasing nuclear half-lives. Clearly, with these ?imitations on the time in wilich to complete an experiment and the fer atoms avallable, many fundanental and important physical and cherical properties are outside the doma in of experimental measurement.

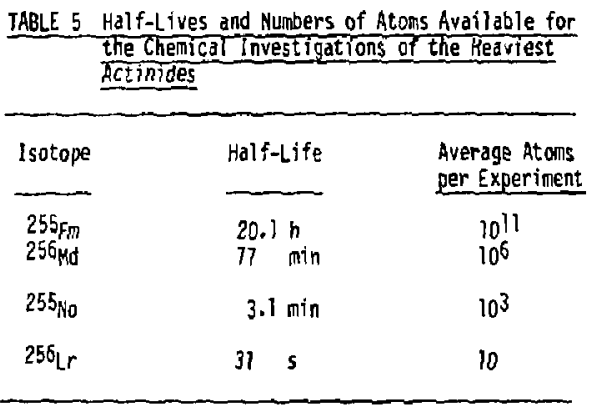

If we observe the chemical behavior of fewer than a hundred atoms, can we be reasonably certain that our observations represent the "true" chemistry of an elenert? A detailed answer to this troublesome question has only recently been addressed. Borg and Dienes $(60)$ considered the rate of approach to a 
thermodynamic equilibrium in an ensemble where only a few atoms of an element are present. Taking a single-step exchange reaction,

$$
M X+Y \underset{k_{2}}{=} \underset{F_{1}}{=} M Y+X,
$$

as one commoniy encountered, they assume a displacentent mechanism illustrated in the simple activation energy diagram of Fig. 5. If $\Delta G^{\dagger}$ was less than $\sim 15$ to $17 \mathrm{kcal}$, the residence time in each state $\mathrm{MX}$ or MY was calculated to be very short and an equilibrium would be rapidly (1 s) reached. This assumes a collision frequency of the sarre magnitude as vibration frequencies, or about $10^{14} \mathrm{~s}^{-1}$. Once equilibrium is reached, the fractional average time an aton spends as MY or $M X$ is proportional to the equilibrium value of $(M Y) /(M X)$. Thus, an experinental measurement of (MY) and (MY) with very few

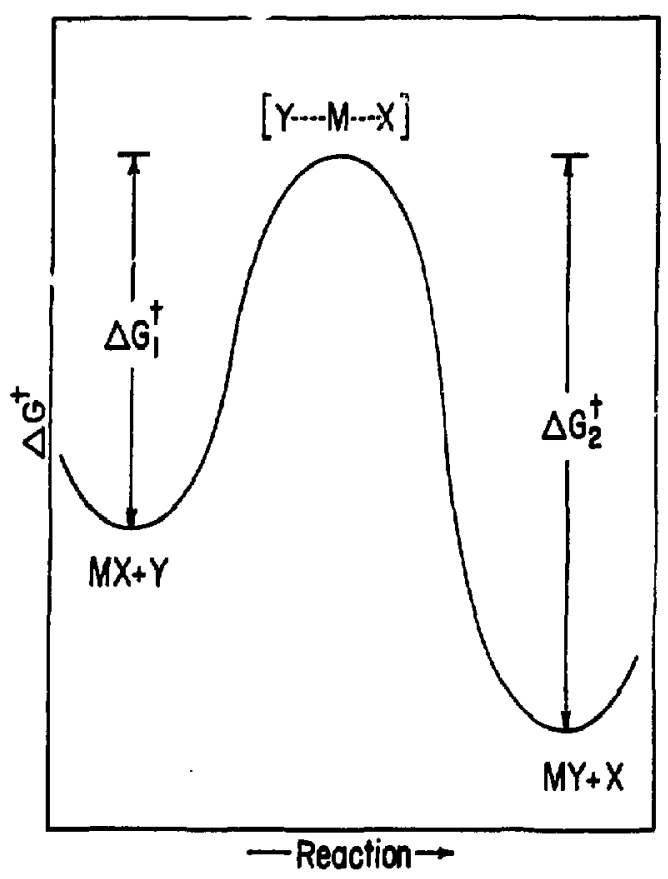

Fig. 5. Activation energy diagram for a single-step exchange reaction. 
atons of M present will yield an equilibrium constant statistically close to the "true" value provided both states are rapidly sampled. They calculated from the binomial law that with as few as io atoms of $M$, the probability of obtaining twice the most probable value was $10 \%$ or less when the fraction of either species was greater than $1 \%$.

\section{FERMIUM}

Several Fm isotopes with half 1 ives of nearly a day to 100 days are available in amounts of $10^{9}$ atoms or more. The nuclides $255_{\mathrm{Fm}}$ and $25 \mathrm{~F}_{\mathrm{m}}$ are conveniently used for chemical investigation of $\mathrm{Fm}$; they are obtainable as products from long neutron irradiations of $242 \mathrm{Pu}$ and $244 \mathrm{~cm}$. The $20-\mathrm{h} 255 \mathrm{Fm}$ is generated by the beta decay of $40 \mathrm{nd} 255 \mathrm{Es}$ produced in the neutron irradiations. By chemically isolating the Es and periodically reseparating Fin from its parent, one can secure a fairly long-term source of 255 in adequate for all tracer experiments.

The ground-state electronic configuration of $F m$ is $5 \underline{f}^{12} \underline{s}^{2}$ or an ${ }^{3} \mathrm{H}_{6}$ level (61). This was established by an atomic-bean measurement of the magnetic monent $g_{j}$ of 3.24-h ${ }^{254} \mathrm{Fm}$. In this elegant measurenent, $\mathrm{FmF}_{3}$ was reduced with $2 r C_{2}$ in an atonic-bean apparatus to produce a bean of neutral Fm atoms. Three magnetic resonances were detected and the best value for $g_{j}$ was calculated. To obtain the level term, it was necessary to extrapolate the mixing due to inteniediate coupling in the electron spin-orbit interactions $(j-j$ and L-S). These extrapolations were made from lower actinides and supplemented by Hartree-Fock calculations for free atons. From similar calculations, the next higher level is predicted to be ${ }^{5}$ y starting about 20,000 $\mathrm{cm}^{-1}$ above the ground state and having the configuration $5 \mathrm{f}^{11} 1_{6 \mathrm{~d}} \mathrm{~s}^{2}$. However, the $f^{2} \underline{s p}$ and $f^{l} s^{2} p$ configurations are very close in energy(5) to the fll $\mathrm{ds}^{2}$ so that $\overline{i t}$ is impossible to unambiguously estimate the next leveT above the ground state.

The electron binding energies of $F m$ have been measured for the $K, L_{1-3}, N_{-5}$, $\mathrm{N}_{6,7}, 0_{1-3}, 0_{4}, 5$, and $P_{2,3}$ shells $(62,63)$. These were determined to an accuracy f 10 eV by conversion-electron spectroscopy in the beta decay of $254 \pi \mathrm{cs}$ to ${ }^{25} \mathrm{Fm}$. A surprisingly iow binding energy for the $\left.P_{2},(6 \mathrm{p}) / 2,3 / 2\right)$ shell of $24+9$ eV was found. Predicted values derived either' from extrapolations of those measured in lower actinides or calculated by Hartree-fock and relativistic local-density methods are about 20 to $60 \mathrm{eV}$ higher in energy. However, relativistic Dirac-Fock calculations with the addition of a Lanb shift correction gave binding energies in excellent agreement with the experimental ones(64). As the authors suggested, a binding energy of $24 \mathrm{eV}$ might provide a possibility for $6 p$ involvenent in chemical and spectroscopic interactin!!s.

The properties of Fn metal and of its solid compounds are for the most part unknown because there are insufficient quantities to prepare even microsamples. In the numerous themochromatographic studies by Zvara and COworkers, the evaporation of $\mathrm{Fm}$ and $\mathrm{Md}$ tracer from malten La at $1150^{\circ} \mathrm{C}$ was compared with the behavior of other selected lanthanides and actinides(65). The volatility of Md and Fm was found to be greater than that of $\mathrm{Cf}$, and $\mathrm{CF}$ was about equivalent to $Y b$ and Eu, All were much more volatile than Am and Ce. A later study at this Laboratory by Hubener(12) extended these studies by comparing the adsorption of elemental Cf, Es, Fm, and Md in the gaseaus state on the Ti surface of a themochromatographic column. Since they had established that for the $s$ and $f$ elenents there was a correspondence between the metallic valence and the deposition temperature, their 
purpose was to characterize the metallic state properties of the heavy actiinides which are available oniy in trace amounts. On the basis of virtually equal deposition temperatures, Hübener concluded that $\mathrm{Cf}, \mathrm{Es}, \mathrm{Fm}$, and $\mathrm{Md}$ were divalent metals, aithough $C f$ condensed at a slightly higher temperature than the other actinides. Ytterbium behaved the same as the Es, Fm, and $\mathrm{Md}$, but $\mathrm{Eu}$ and $\mathrm{Sm}$ condensed at a temperature $300^{\circ} \mathrm{C}$ higher. The evaporation rates of Cf and Fm from molten $U$ have also been found to be equal (66) wich again shows that if $[f$ is to be considered a divalent metal, then 50 should Fin metal.

The separation methods for Fm are the same as those used for separat ing other trivalent lanthanides and actinides. Additional methods for separating trivalent actinides from lanthanides are given in the Separation and Purification section on einsteinium. For separating the adjacent elements, Es and Md, a high-resolution chronatographic method is necessary. Either ion exchange, using strongly acidic resins (67), or extraction chromatography employing alkylphosphoric acids(68) is strongly preferred. A complexing agent (a-hydroxyisobutyric acid) is required to selectively elute the actinides from cation-exchange resins. The separation factors, defined as the ratio of the distributian coefficients of two metal jons, are small for both cation exchange and extraction chrcmatography. These factors range from 1.7 to 2.04 for Es-Fm separatioris using a Dowex.50 cation exchanger (67) or extraction chromatography with $\mathrm{HCl}$ as the eluant and bis\{2-ethy?hexyl)phosphoric acid diluted with heptane as the extractant (69). The Frild separation factors obtained by these two methods were 1.4 and 4.0 , respectively $(67,69)$.

The solution chemistry of $\mathrm{Fm}$ deals largely with the highly-stable tripositive oxidation state, although the dipositive state is also known. Formation constants for citrate complexes(70) and the first hydrolysis constant ha!e been accurately determined for $\overline{\mathrm{Fm}}^{3}+(71,72)$. Since the formation and hycrolysis constants for $\mathrm{Am}, \mathrm{Cm}, \mathrm{Cf}$, and $\mathrm{E}$ were measured stmultaneously with those for $\mathrm{Fm}$, the complex strengths of many of the trivalent ac:inides can be compared(J2). All constants were determined at an ionic strength of $\mu=0.1$ in a perchlorate medium by measuring the particioning of the radioactive tracers between a thenoyltrifluoroacetonate-benzene phase and the aqueous phase. The results for Fom may be expressed as follows:

$$
\begin{array}{ll}
\mathrm{Fm}^{3+}+\mathrm{H}_{2} \mathrm{O} \rightleftharpoons \mathrm{FmOH}^{2+}+\mathrm{H}^{+} ; & \log \mathrm{K}=-3.80 \pm 0.2 \\
\mathrm{Fm}^{3+}+2 \mathrm{H}_{3} \mathrm{Cit} \rightleftharpoons \mathrm{Fm}\left(\mathrm{HCit}_{2}\right)^{2-}+5 \mathrm{H}^{+} ; & \log \beta_{1}=11.17 \\
\mathrm{Fm}^{3+}+2 \mathrm{H}_{3} \mathrm{Cit} \rightleftharpoons \mathrm{FmCit}_{2}^{3-}+6 \mathrm{H}^{+} ; & \log \beta_{1}=12.40
\end{array}
$$

Compared to the other actinide ions investigated, fin formed stronger complexes with citrate and hydroxyl ions because of its smaller ionic radius. The smaller radius is a direct consequence of the increased nuclear charge with partial shielding of the outermost $6 p$ electrons by the inner $f$ electrons.

The reduction of $\mathrm{Fm}^{3+}$ to $\mathrm{Fm}^{2+}$ was first reported in 1972 by N. B. Mikheev and coworkers (73). The reduction was accomplished with Mg metal in the presence of $5 m^{37}$ which was coreduced in an aqueous-ethanol solution. Identification of the divalent state of $F \pi$ was established by determining the extent of its cocrystallization with $\mathrm{SmCl}_{2}$ and this was compared to the amount of tracer $5 r^{2+}$ al so carried with $S \mathrm{SCl}_{2}$. A milder reductant, Eu ${ }^{2+}$, failed to reduce $\mathrm{im}^{3+}$ which placed the standard reduction potential of $\mathrm{Fm}^{3}{ }^{3+}$ between $\mathrm{Eu}^{2+}$ and $5 \mathrm{~m}^{2+}$ or -0.43 to $-1.55 \mathrm{~V}$ relative to the standard $\mathrm{Pt}, \mathrm{H}_{2} \mathrm{H}^{+}$elec- 
trode. Later work(74) by these scientists narrowed the range to between -0.64 and $-1.15 \mathrm{~V}$ and, most recently, they were able to estimate the potential was the same as the $\mathrm{Yb}^{3+} \rightarrow \mathrm{yb}^{2+}$ couple within $0.02 \mathrm{~V}$, or $-1.15 \mathrm{~V}(35,-$

16). This was accomplished by measuring the ratio of Fm(III) to Fm(II) by cocrystallization of $\mathrm{Fm}(\mathrm{II})$ with $\mathrm{SrCl}$, while changing the ratio of $Y b$ (II)/Yb(III) in each experiment. The difference between the standard potentials of $F m$ and $Y b$ is then easily detenmined from the Nernst equation. The reduction of $\mathrm{Fm}$ to a divalent ion with $\mathrm{SmCl}_{2}$ has also been observed recently by Hulet et al. (7I).

In further work related to the divalent state, the electrode potential for the reduction of $\mathrm{Fm}^{2+}$ to $\mathrm{Fm}^{0}$ has been measured by Samhoun and David (78). Over a period of years, they developed and rafined a radiopolarographic technique for detemining half-wave potentials at a dropping-Hg cathode. In addition to $\mathrm{Fm}$, they have measured either cthe III $\rightarrow 0$ or II $\rightarrow 0$ potential for all transplutonium actinudes except $N_{0}$ and $\operatorname{Lr}(53,78,79)$. The polarograph for $\mathrm{Fm}$ is shown in Fig. 5. The electrochemical reaction taking place at a reversible electrode can be deduced from the slope of the polarographic wave. Specifically, the number of electrons exchanged at the electrode, based on the Nernst equation, is obtained from this slope. From their andiysis of the polarograms, there were three electrons involved in the electro-chemical reduction of the trivalent ions of the elements Am through Es and only two electrons for the reduction of $\mathrm{Fm}$. This implies that $\mathrm{Fm}^{3+}$ was first reduced to $\mathrm{Fm}^{2+}$ before being further reduced to metal. The $[I I-11$

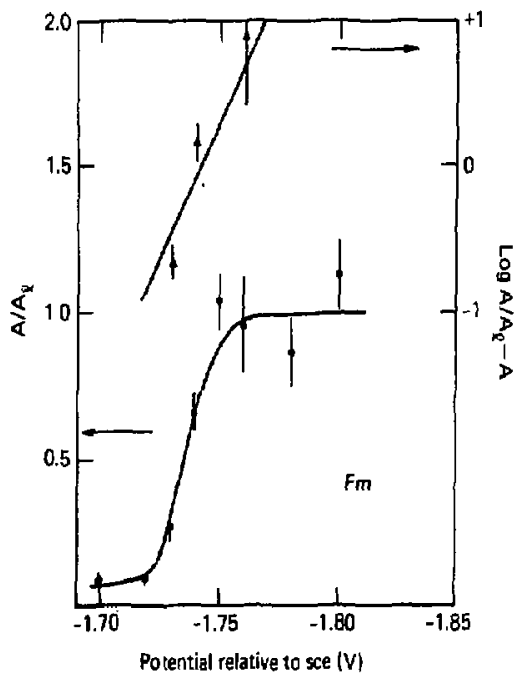

Fig. 6. Distribution of $\mathrm{Fm}$ as a function of applied voltage between mercury in a dropping $\mathrm{Hg}$ cathode and $0.1 \mathrm{H}$ tetramethyl amoniun perchlorate at $\mathrm{pH}=2.4$. The slope of the logarithmically-transfomed line indicates two electrons were exchanged in the electrolys is reaction (Ref. 79). 
reduction step is not detected by this radiopolarographic technique because both the III and II ions are in the solutiun phase, whereas the measured parameter ir the distribution of the tracer between the aqueous and $\mathrm{Hg}$ phase. The half-wave potentials measured by this method include the amalgamation potential of the metal-mercury reaction. The potential for the overall process for $\mathrm{Fm}$, i.e.

$$
\mathrm{Fm}^{2+}+2 e^{-}=\mathrm{Fm}(\mathrm{Hg}),
$$

was found to be $+1.474 \mathrm{~V}$ with reference to the standard hydrogen electrode. The amalgamation potential was estimated to be $0.90 \mathrm{~V}$ by using the netall ic radius as a correlating parameter and interpolating within a series of divalent elements with known amalgamation potentials(52). This correlation is shown in Fig. 7. The standard el ectrode potential is then given as -2.37 $V$ for the $\mathrm{Fm}^{2+}+2 \mathrm{e}^{-}=\mathrm{Fm}^{0}$ reaction. The authors' estimated $5 \mathrm{mV}$ accuracy for the measured half-wave potential seens reasonable, but there is a much larger uncertainty in the estimated amalgamation potential.

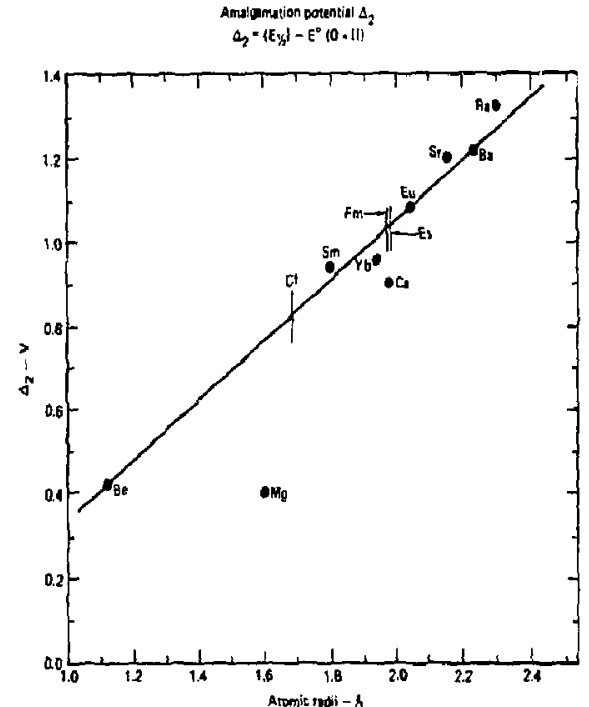

Fig. 7. Amalgamation potentials, $\Delta_{2}$, derived from experimantal data are plotted as a function of the atomic (metallic) radii. The amalgamation potential for $\mathrm{Fm}$ is obtained by using an estimated radius. Partially redrann from Ref. (52).

\section{MEHIDELEVIUH}

The isotope $256 \mathrm{Wd}$ is nearly always employed for chenical studies of this element. Besides having a convenient half-life of $77 \mathrm{~min}$, this nucilide can be made with millibarn cross sections by a number of nuclear reactions between light and heavy ions with actinide target nuclej. We have found that 
the bombardment of fractions of a microgram of 254Es with intense alphaparticle beams will produce $-10^{6}$ atoms of 256 wd in one to two hours of irradiation time. The 256Md is most easily detected through spontaneous fission arising from the ingrowth of its electrch-captui $\bar{c}$ daughtiei, $256 \mathrm{Fm}$. A difficulty with using spontaneous-fission counting to determine the Md content of samples is that the growth and decay of fission radioactivity in each sample must be followed with time in order to resolve the amounts of Md and Fm initially present. However, alpha-particles of a distinctive energy coming from a lo\% alpha-decay branch can also be used to identify 256 Md in a mixture of actinide tracers.

The volatility of mendelevium metal has been compared with that of other actinide metals $(12,65)$; these results were described in the fermium section. Because of the high volatility found, mendelevium was believed to be a divalent metal.

There are no experimental verifications of the electronic structure of Md, but this has been calculated by several methods to be $5 f^{1} / 3 s^{2}$ in which the ground state level is ${ }^{2} F_{7 / 2}(\underline{5})$.

The separation of Md from the other actinides can be accomplished either by reduction of $\mathrm{Md}^{3+}$ to the divalent state $(80)$ or by chromatographic separa. tions with Md remaining in the tripositive state. Historically, Md ${ }^{3+}$ has been separated in columins of cation-exchange resin by elution with a-hydroxyisobutyric acid soluzions(67). This method is still widely used even though extraction chromatography requires less effort and attention to technique. Horwitz and coworkers(69) developed a highly-efficient and rapid separation of $\mathrm{Hd}^{3+}$ by employing $\mathrm{HNO}_{3}$ elutions from columns of silica porder ponder saturated with an organic extractant, bis(2-ethylhexyl)phosphoric acid. The separation of Md from $E_{5}$ and $F m$ could be completed in under 20 minutes and had the advantage of providing final solutions of Md free of complexing agents that might be an interference in subsequent experiments.

When the divalent state of Md was first discovered, extraction chronatography was used to prove that the behavior of $\mathrm{Md}^{2+}$ was dissimilar to that of $\mathrm{Es}^{3+}$ and $\mathrm{Fm}^{3+}(80)$. The extractant, bis (2-ethylhexyl)phosphoric acid (HOEHP), has a much lower affinity for divalent ions than it does for the tri- and tetravalent ones. Thus, the extraction of $\mathrm{Md}^{2+}$ is much ponrer than the extraction of the neighboring tripositive actinides as indicated by the results shown in Table 6 . This becane the basis for a separation method in which tracer Md in $0.1 \mathrm{M} \mathrm{HCl}$ is reduced by fresh Jones Reductor in the upper half of an extraction column containing HDEHP absorbed on a fluorocarbon powder in the lower half. Mendelevium, in the dipositive state, is rapidly eluted with $0.1 \mathrm{H} \mathrm{HCl}$ whereas the other actinides are retained by the extractant. The separation is quickly performed, but the Md contains small amounts of $\mathrm{Zn}^{2+}$ from the Jones Reductor and also $\mathrm{Eu}^{2+}$, which was added prior to the elution to prevent reoxidation of $\mathrm{Md}^{2+}$ by the extractant. 
TABLE 6. Comparison of the Extraction Behavior of tracer Einstel in um, Fermfum, and Mendelevium after Treatment with Various Reducing Agents. The Eolumn-Elution Method of Extraction Chromatography Was Used with the Extractant HDEHP Adsorbed on a Column Bed of a Fluoroplastic Powder Ref. 80

\begin{tabular}{|c|c|c|c|}
\hline \multirow[t]{2}{*}{$\begin{array}{l}\text { Conditions for } \\
\text { Reduction }\end{array}$} & \multirow{2}{*}{$\begin{array}{c}\text { Standard Potential } \\
\text { of Reducing Agent } \\
\text { (volts) }\end{array}$} & \multicolumn{2}{|c|}{$\begin{array}{l}\text { 8 Non-Extracted By } \\
\text { HDEHP Column }\end{array}$} \\
\hline & & Md & $\overline{E s-F m}$ \\
\hline $\begin{array}{l}\text { In }(\mathrm{Hg}) \text { amal gam in } \\
\text { upper half of extrac- } \\
\text { tion column }\end{array}$ & -0.763 & 77 & 0.10 \\
\hline 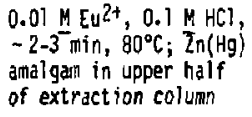 & -0.43 & 75 & 0.10 \\
\hline $\begin{array}{l}0.6 \mathrm{MCr}{ }^{2+}, 0.1 \mathrm{M} \mathrm{HCl}, \\
-2 \text { min, } 25^{\circ} \mathrm{C} \text {; extrac- } \\
\text { tion column prewashed } \\
\text { with } 0.6 \mathrm{~N} \mathrm{Cr}^{2+} \text { in } 0.1 \\
\mathrm{M} \mathrm{HCl}\end{array}$ & -0.41 & 99 & 0.56 \\
\hline
\end{tabular}

The solution chenistry of the trivalent oxidation state has not been investigated beyond its behavior in the separation procedures described above. All observations indicate that $\mathrm{Md}^{3+}$ is a "nomal" act inide rith an ionic radius slightly less than that of $\mathrm{Fm}$. As might be expected, attempts to oxidize $\mathrm{Md}^{3+}$ with sodium bismuthate failed to show any evidence for $\mathrm{Md}^{4+}(80)$.

The divalent oxidation state was the first found for any member of the actinide series $(80,81)$ and, therefore, stirred a strong theoretical and experimental effort to establish the reasons for the unexpected stability of this state in Md and, subsequently, in the adjacent actinides. We shall summarize the interpretations for divalency in the heaviest actinides in a later section of this review, but in this section, anly the known properties of $\mathrm{Md} 2+$ will be presented.

In the earliest experiments with $\mathrm{Md}^{2+}$, rough measurements were made of the reduction potential for the half-reaction

$$
\mathrm{Hd}^{3+}+\mathrm{e}^{-}=\mathrm{Md}^{2+} \text {. }
$$

The first measurement gave a reduction potential of $-0.2 \mathrm{~V}$ with respect to the standard hydrogen electrode $(80)$. This value was obtained from determining the equilibrium concentration of each metal ion in the reaction

$$
\mathrm{V}^{2+}+\mathrm{Md}^{3+} \longrightarrow \mathrm{V}^{3+}+\mathrm{Hd} \mathrm{d}^{2+}
$$

and then calculating the equilibrium constant. After entering the equilibrium constant into the Hernst equation, it was found that $1^{3+}$ was a better 
reducing agent than $\mathrm{Md}^{2}+$ by about $0.07 \mathrm{~V}$. In other experiments, Maly observed the complete reduction of $\mathrm{Md}^{3+}$ with $\mathrm{V}^{2+}$ but the reduction was inconplete when $\mathrm{Ti}^{3+}$ was used $(81)$. From these abservations, he concluded the standard reduction potentiat of $\mathrm{Md}^{3+}$ was close to -0.1 volt. The standard potentials obtained by both groups are in reasonable agreenent and, most inportantly, they conclusively show that the stability of $\mathrm{Hd}^{2+}$ is greater than any lanthanide(II) ion. This finding was surprising since divalency in the lanthanides is mainly associated with the special stability given by the half-filled and fully-filled f-electron shell. Divalent $\mathrm{Hd}$ ions are at least one electron short of the stable $5 f^{14}$ configuration.

Additional experiments, which may not be clecrly relevant to the divalent oxidation state, include the reduction of $\mathrm{Md}^{3 \mathrm{r}}$ to $\mathrm{Md}(\mathrm{Hg})$ by sodium amalgans and by electrolysis(82). Both the extraction experiments with $\mathrm{Na}$ amalgams and the electrolysis at a $\mathrm{Hg}$ cathode indicated a large enrichment of Md in the $\mathrm{Hg}$ phase relative to that of $\mathrm{Np}, \mathrm{Pu}, \mathrm{Am}, \mathrm{Cm}$, and Cf. The percentages of Es and $\mathrm{Fm}$ in the sodium amalgam were not greatly different from the percentage of Md. But a clear enrichment of Md was obtained in the electrolys is experiments because the initial rate of amalgamation was much larger for $\mathrm{Md}$ than for Es and Fm.

Recently, new electrochemical experiments were carried out with $\mathrm{Md}$ in which controlled-potential electrolysis was used to study the reduction of $\mathrm{Md}^{3}+$ to the metallic state in a $\mathrm{hg}$ amalgam $(79,33)$. Half-waye potentiais were measured by radiocoulometry and radiopolarography in the presence of noncomplexing and weak and strong complexing agents. The radiopolarogram obtained for $\mathrm{Md}$ in a noncomplexing medium is presented in Fig. 8 . The half-wave putential for Fm was remeasured at the sane time as that of Md because of its presence as a decay product of $256 \mathrm{Md}$. The results showed that the reduction potential of Md was about $10 \mathrm{mV}$ more negative than $\mathrm{Fm}$ and that no significant difference was observed upon changing the medium from $\mathrm{ClO}_{4}^{-}$to $\mathrm{Cl}^{-}$. In citrate solutions, a shift of $90 \mathrm{mV}$ was obtained for $\mathrm{kd}$ which is about the same shift seen with $F m$ and $B a$ ions in a citrate medium. The slooe of the logarithmically transformed wave was $30 \mathrm{mV}$ for Md and Fm and, for the reasons noted in the section on $F m$, this siope corresponds to a twoelectron exchange at the electrode. These results demonstrate that the electrochenical behavior of $\mathrm{Md}$ is very similar to that of $\mathrm{Fm}$ and can be sumarized in the equation

$$
\mathrm{Md}^{2+}+2 \mathrm{e}^{-}=\mathrm{Md}(\mathrm{Hg}) ; \quad \mathrm{E}^{0}=-1.50 \mathrm{~V} .
$$

If a $0.90 \mathrm{~V}$ amaigamation potential is assumed, then a standard reduction potential of $-2.40 \mathrm{~V}$ is obtained.

In addition to the di- and trivalent ions of Mo, a stable monovalent ion was reported by Mikheev et al, in 1972(84). This oxidation state was indicated in the cocrystallization of $\mathrm{Md}$ with $\mathrm{CsCl}_{5}$ and $\mathrm{RbCl}$ after the coreduction of $\mathrm{Md}^{3+}$ and $\mathrm{Sm}^{3+}$ with $\mathrm{Mg}$ in an ethanol-7 $\mathrm{MHCl}$ solution. Mendelevium was also found enriched in RbjPtCi 6 precipitates, a specific carrier for the larger ions of the alkali metals. These results were explained by a stabilization of the monovalent ion due to completing the $f$ shell which would give the sf 14 electronic configuration.

In response to the totally negative findings from others' studies $(77,83)$, Mikheev and his colleagues(85) carried out new cocrystallizations of Md with $\mathrm{NaCl}$ and $\mathrm{KCl}$ after reducing with $\mathrm{Eu}^{2+}$ or $\mathrm{Yb} 2+$. The $\mathrm{MaCl}$ or $\mathrm{KCl}$ salts were forced to crystallize by hesilily salting the nearly neutral $\mathrm{H}_{2} \mathrm{O}$ - 
ethanol solutions, containing tracer $\mathrm{Md}$, with $4 \mathrm{MLICl}$. Because anomalous mixed crystals were not formed, they again claimed the cocrystallization of Md with $\mathrm{NaCl}$ or KCl demonstrated the presence of $\mathrm{Md}^{+}$.

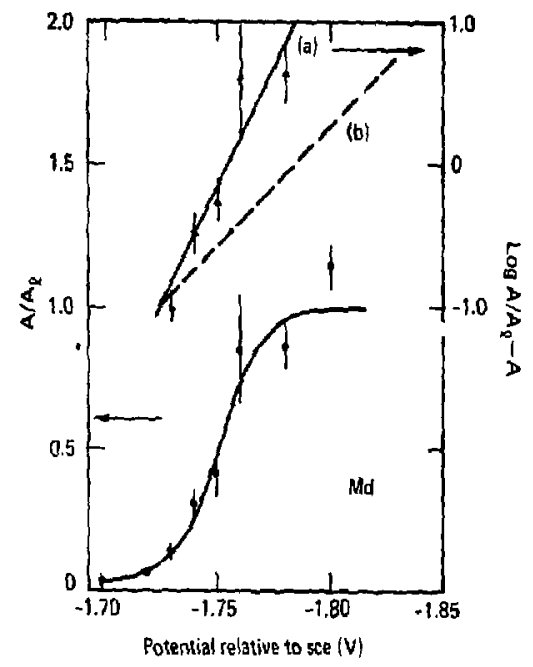

Fig. 8. Distribution of $h d$ as a function of applied yoltage between mercury in a dropping $\mathrm{Hg}$ cathode and $0.1 \mathrm{M}$ tetramethyl amonium perchlorate at $p h=2.4$. The siope of the logarithmically-transformed line indicates the number of electrons exchanged in the electrolysis reacticn. The slope of line (a) is $30 \mathrm{~m}$, and (b) is $60 \mathrm{mV}$, which corresponds to a one-electron reduction (Ref. 79 ?.

The $\mathrm{RbCl}$ cocrystallizations and $\mathrm{Rb}_{2} \mathrm{PtCl}_{6}$ coprecipitations of Ref. 84 were recently repeated and an extensive series of new experiments were performed in which attempts - were sade to prepare $\mathrm{Md}^{+}$by reduction with $\mathrm{SnCl}_{2}$ in an ethanolic or fused KCl medium(37). After the reductions, the coprecipitation behavior of Hd was compared with the behavior of tracer amounts of ES, Fin, Eu, Sr, Y, and $C_{5}$, also present in the same solution. A large number of experinents showed that Md consistently foljowed the behavior of $\mathrm{Fm}^{2+}$, Eu ${ }^{2+}$, and $\mathrm{Sr}^{2+}$ rather than the behavior of $\mathrm{Cs}^{+}$. The most telling experiment was the precipitation of $\mathrm{Rb}_{2} \mathrm{PtCl}_{6}$ after reduction of $\mathrm{Md}^{3+}$ with $\mathrm{Sm}^{2+}$. The distribution of the tracer elements between the precipitate and an a5* ethanol solution is given in the form of a ratio in Table 7 . These results clearly demonstrate that $\mathrm{Md}$ did not coprecipitate with $\mathrm{Rb}_{2} \mathrm{PtCl}_{6}$, whereas virtually all of the Cs did so. The overall conclusion of this work was that Md cannot be reduced to a monovalent ion with $\mathrm{Sm}^{2+}$ and, therefore, the earlier claim for $\mathrm{Hd}^{+}$was unsubstantiated. 
TABLE 7 Distribytion of Tracer Elements After Reduction with $\mathrm{Sm}^{2}$ and Coprecipitation with $\mathrm{Rb}_{2} \mathrm{ptCl}_{2}$ in B5s Ethanol (Ref. 17)

\begin{tabular}{|c|c|c|c|c|c|c|}
\hline $\mathrm{Fm}$ & Md & $\begin{array}{l}\text { Dist } \\
\text { Eu }\end{array}$ & $\begin{array}{c}\text { ution } \\
S r\end{array}$ & io for & Es & Cs \\
\hline 0.004 & 0.005 & 0.006 & 0.012 & 0.017 & 0.033 & 110 \\
\hline
\end{tabular}

This same conclusion was reached also by Samhoun et al. (83) and David and coworkers $(79)$ on the basis of their electrochenical investigations of $\mathrm{Md}$, which we described earlier. If the potential for the reaction $\mathrm{Md}^{+}+\mathrm{e}^{*}=$ Md was more positive than $-1.5 \mathrm{~V}$, it would have been observed in the electrochemical reductions. Furthemore, the logarithmic slope of the Md reduction waves could not be fitted to a slope of $60 \mathrm{~mW}$ expected for a one-electron change. And lastly, the shifts in potential caused by complexing Md with either citrate or chloride ions were consistent with it being a divalent ion and not with it being either a cesiuni-like or silver-like ion.

Because of the large number and variety of negative results, the weight of evidence is heavily against $\mathrm{Md}^{+}$, but the attempts to produce a monovalent state have the positive effect of setting limits on its stability. From the linits obtained, we can then make an estimate of the stabjlity of the $5 f^{14}$ configuration relative to the $5 \mathrm{f} 137 \mathrm{~s}$. Presumably, the $\mathrm{f}^{13 \mathrm{~s}}$ configuration lies lower in energy than the $f$ la because there is no obvious stabilization of a monovalent state due to a possible closing of the $5 f$ shell. The divalent ion is then at least $1.3 \mathrm{~V}$ more stable than the monovalent ion.

\section{NOBELIUM}

The principle isotope of nobelium produced for investigations of its chem:cal properties is $3.1-$ min 255 No. In the earliest studies $(85)$, this nuclide was synthesized by irradiating 244 $\mathrm{Pu}$ with $97-\mathrm{MeV}$ i5o ions, but larger yields were later obtained in bombardments of $249^{\circ} \mathrm{Cf}$ targets with 73 - MeV $12 \mathrm{C}$ jons $(87)$. From the latter nuclear reaction, about 1200 atoms of $255_{\mathrm{NO}_{0}}$ were colfected every ten minutes. Of these 1200 atoms, only 3 to $20 \%$ were detected after the chenical experiments because of losses by radioactive decay, losses in the experiments, and a $30 \%$ geometry for counting alpha particies emitted in the decay of this isotope. To obtain results that were were statistically significant, the experiments were repeated until the required accuracy was attained.

Future work with No may require techniques or procedures of greater complexity than the one-step chemical mathods used in past studies. The author believes that $259 \mathrm{No}$, because of its $1-\mathrm{h}$ half-life, would penit these more extensive investigations of No chemistry. Approximately 700 atoms can be made in a two-hour irradiation of $248 \mathrm{Cm}$ with $96-\mathrm{MeV} 180$ ions. In combination with the long half-life, this number of atons is sufficient to pernit a broader range of experiments to be perfomed.

A central feature in the chemistry of No is the dominance of the divaient oxidation state(86). In this respect, $N_{0}$ is unique within the lanthanide and actinide series, since none of the other twenty-seven members possess a 
highly-stable divalent ion. The electronic configuration of the neutral

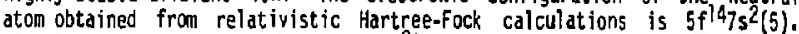
Clearly, the special stability of $\mathrm{No}^{2+}$ must arise from the difficutty in ionizing an $f$ valence electron from the completed $5 f$ shell. Thus, pairing of the last electron to close the shell results in the $f$ electron levels taking a rather abrupt drop in energy below the fenmi surfaçe.

The separation of No from other actinide elenents is based entirely on the dissimilar behavior of $\mathrm{No}^{2+}$ in comparison with the tripositive actinide ions. Without the addition of strong oxidants, No will be present as $\mathrm{No}^{2+}$ in acidic solutions and will have the general chemical properties of Group [IA eienents in the Periodic Table. We have found that the extraction chromatographic method described in the section on Mo provides an effective separation from all other actinides and biothanides. In ccntrast to Hd, reducing agents are unnecessary in separating No by this extraction chemistry.

The solution chenistry of tho was explored shortly after the discovery of divalent Md(B6). Subsequent studies inciude an estimation of the II $\hat{i}-I I$ reduction potential(88), aqueous complexing with carboxylate ions $(89)$, and a determination of $\overline{\mathrm{NO}} 2+$ extraction and ion-exchange behavior in comparison with the alkaline earths(87). The first studies(86) indicated that the nomal state of No in aqueous solution was that of a divalent ion. Nobeljun was coprecipitated with $\mathrm{BaSO}_{4}$ but not with $\mathrm{LaF}_{3}$. After oxidation with $\mathrm{Ce}+4$, a large fraction of the No coprecipitated with LaFy. This behavior is consistent with a change in oxidetion state from (II) to (IIJ). An elution position of No relative to tracer quantities of $\mathrm{Es}, \mathrm{Y}, \mathrm{Sr}, \mathrm{Ba}$, and Ra ( $\mathrm{Fig}$. 9) showed that No did not elute before Es as nould be expected of a tripositive actinide ion.

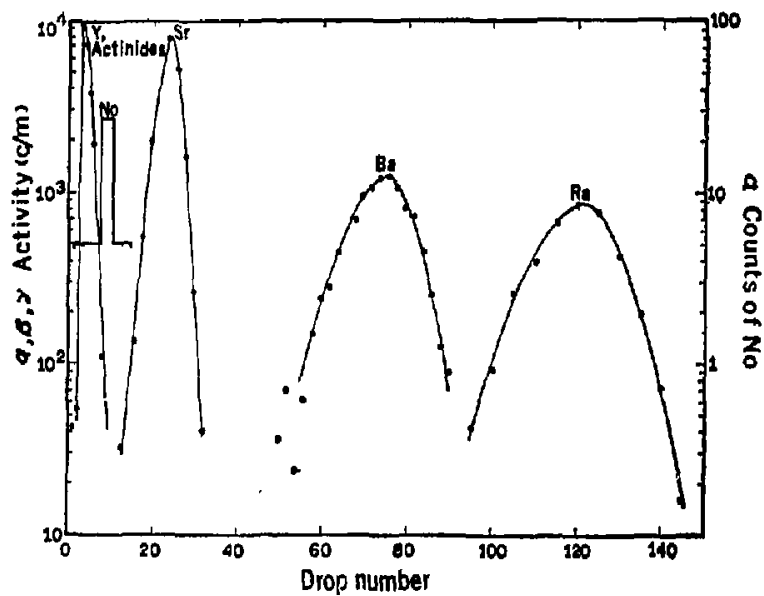

Fig. 9. Elution of nobelium from a heated $\left(B 0^{\circ} \mathrm{C}\right)$ Dowex $\left.50-x\right\rangle 72$ cation-exchange columin with $1.9 \mathrm{M}$ ammonium $a$-hydraxyisobutyrate ( $\mathrm{pH}$ 4.8). (Reprintec with the pemission of Science (Ref. 86): Copyrightit 1968 by the American Association for the Advancenlent of Sclence) 
The standard reduction potential of the $\mathrm{No}^{3+} / \mathrm{Ho}^{2+}$ couple in aqueous solution was estimated by silya and coworkers (88) from the extractibility of No after treatment with a variety of oxidants. The distinction between $\mathrm{No}^{2+}$ and $\mathrm{No}^{3+}$ was made on the basis of the affinity of the extractant, bis(2-ethylhexyl) phosphoric acid, for highly-charged cations. In $0.1 \mathrm{M}$ acid, mono- and dipositive ions are poorly extracted, wereas the tri- and tetrapositive ians are strongly absorbed in the extractant. In comparison with the behavior of the tracer ions of $\mathrm{Ra}, \mathrm{Tl}, \mathrm{Ce}, \mathrm{Cm}$, and $\mathrm{Cf}$ (see Fig. 10) it was shown that No was not fully extracted until $\mathrm{H}_{5} \mathrm{IO}_{6}$ (standard potential $=1.6 \mathrm{~V} / 3$ was used as an oxidant. Chromate and $\mathrm{HBrO}_{3}$ partially oxidized $\mathrm{NO}^{2+}$ to $\mathrm{NO}^{3+}$. From these observations, a potential of 1.4 to $1.5 \mathrm{~V}$ was estimated for the couple.

The extraction behavior of $\mathrm{Ho}^{2+}$ in a tri-n-octylamine-HCl system was compared with that of divalent $\mathrm{Hg}, \mathrm{Cd}, \mathrm{Cu}, \mathrm{CO}$, and $\mathrm{Ba}(87)$. This experiment provided a test of the chloride complex strength of $\overline{K_{0}} 2+$ because the anine anionexchanger will only extract anionic species. It was found that $\mathrm{Ba}^{2+}$ and $\mathrm{No}^{2+}$ were not extractable over a range of 0.2 io $10 \mathrm{H} \mathrm{HCl}$, while the other divalent ions of $\mathrm{Hg}, \mathrm{Cd}, \mathrm{Cu}$, and co were strongly extracted. This implies noncomplexing of wo in the chloride medium which is a characteristic of the alkaline earths.

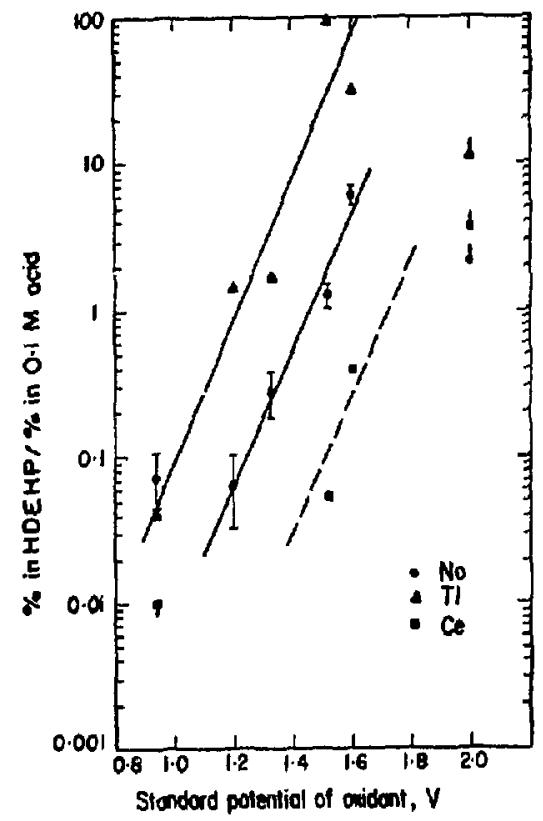

Fig. 10. Aatio of the percent of nobel ium, thallium, and cerium extracted into the organic phase (HDEHP) to the percent left in the $-0.1 \mathrm{H}$ acid phase versus the standard potential of the oxidant used. Reprinted with the permission of Pergamon Press (Ref. 88). 
The elution position of $\mathrm{NO}^{2+}$ from a cation-exchange resin with $4 \mathrm{MHCl}$ eluant was compared with the elution positions of $\mathrm{Be}^{2+}, \mathrm{Mg}^{2+}, \mathrm{Ca}^{2+}, \mathrm{Sr}^{2+}, \mathrm{Ba}^{2+}$, and $\mathrm{Ra}^{2+}(87)$. The $\mathrm{No}^{2+}$ ions eluted at exactly the $\mathrm{Ca}^{2+}$ position. Similar colurin elution experiments, using bis(2-ethylhexy1)phosphoric acid (HDEHP) adsorbed on an inert supoort material and $0.025 \mathrm{M} \mathrm{HCl}$ as the elutitis acid, showed $\mathrm{No}^{2+}$ eluting between $\mathrm{Ca}^{2+}$ and $\mathrm{Sr}^{2+}$. Thes: elution curves are illustrated in Fig. 11. With the same extractant, the distribution coefficient for $\mathrm{ll}_{0}{ }^{2+}$ was measured as a function of hydrogen-ion concentration. From the mass-action expression for the ion exchange, a slope of +2 was obtained from tne line describing the $\log$ of the distribution coefficients vs. pH. The extraction of $\mathrm{NO}^{2+}$ is second power with respect to the $\mathrm{H}^{+}$concentration, thus indicating : charge state of two for No ber: use of the cation-exchange mechanism for extraction in this systerl.

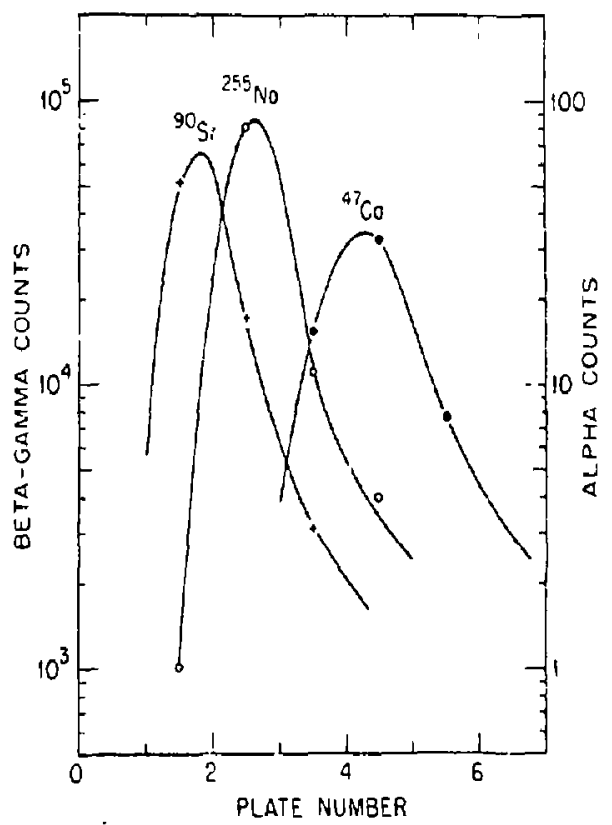

Fig. 11. Elution of $\mathrm{No}^{2+}, \mathrm{Ca}^{2+}$, and $\mathrm{Sr}^{2+}$ with $0.025 \mathrm{M} \mathrm{HCl}$ from a

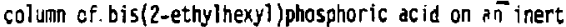
support. Reprinted with the penmission of Inorganic Chemistry (Ref, B7).

Silva and coworkers(87) noted that other investigators had shown a linear correlation between the $\log$ of the distribution coefficients of the alkal ine earths and their ionic raditi. This appeared to be the case werever a pure cation-exchange mechanism governed the distributions between phases and, hence, was applicabie to distributions obtained with either cation-exchange 
resins or extractants. In Fig. $12, \log 0$ is plotted as a function of lonic radius for the extraction of yarious dipositive cations into 0.1 H HOEHP from aqueous solutions. The measured distribution coefficient for ${ }^{-} \mathrm{HO}^{2+}$, when placed on the correlation line, gave an ionic radius of $0.11 \mathrm{~m}$. If the distribution coefficients from their ion-exchange elutions were used, the ionic radius of $\mathrm{No}^{2+}$ would be the same as that of $\mathrm{Ca}^{2+}(0.10 \mathrm{~nm})$, since both ions have the same elution position. An ionic radius of $0.11 \mathrm{~mm}$ was also obtained by applying Pauling's correction to the radius of the outermost, $6 p_{3 / 2}$ shell, which was calculated from a relativistic radial wave function (Hartree-FockSlater). The calculated ionic radius is in agreenent with the radii derived from their solvent-extraction and ion-exchange results. A radius of $0.11 \mathrm{~nm}$ for $\mathrm{NO}^{2+} \mathrm{Cas}$ be compared with 0.103 nn found for $\mathrm{Yb}^{2+}(90)$, the lanthanide homolog of No. Insertion of the No24 ionic radius into an empirical form of the Born equation gave a single-ion heat of hydration of $-1490 \mathrm{~kJ}$ mole-l.

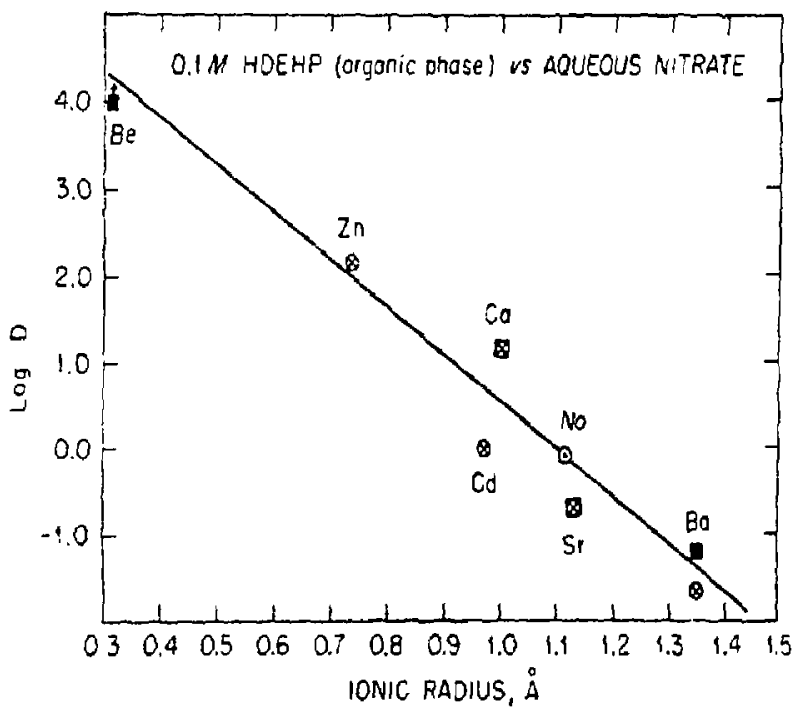

Fig. '2. $\log 0$ us. ionic radius for typical divalent cations in the bis(2-ethylhexyl)phosphoric acid-aqueous nitrate system. Reprinted with the permission of Inorganic Chenistry (Ref. 87).

The ability of No2+ to form complexes with citrate, oxalate, and acetate ions in an aqueous solution of $0.5 \mathrm{MHHaNO}$ was investigated by McOowell and coworkers $(89)$. The complex strengths of Ca $2+$ and $\mathrm{Sr}^{2+}$ with these carboxylate jons were measured under the same conditions for comparison with the No results. The formation constants they obtained are given in labla 8 and indicate for each arion, the complexing tendency of $\mathrm{NO}^{2+}$ is between that of $\mathrm{Ca}^{2+}$ and $\mathrm{Sr}^{2+}$ with $\mathrm{SH}^{2+}$ being slightly more favored. 
$\frac{\text { TABLE } 8 \text { Complex Formation Constants for } \mathrm{Ho}^{2+}, \mathrm{Ca}^{2+} \text {, and } \mathrm{Sr}^{2+}}{\text { from Distribution Data (Ref. } 89)^{2}}$

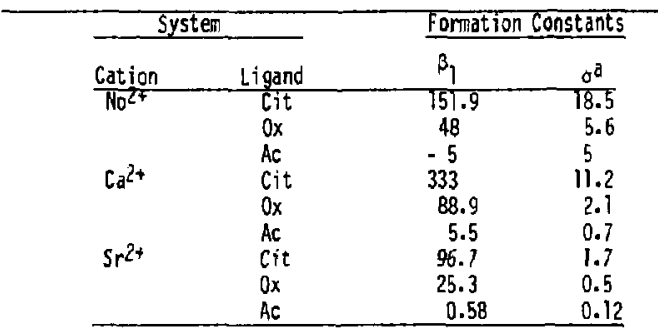

astandard deviation of fitting of $\beta_{\text {q }}$.

The standard potential for the reduction of $\mathrm{No}^{2+}$ to $\mathrm{No}(\mathrm{Hg})$ was measured by a modified radiopolarographic technique(91). Usually, the half-wave potential is detemined by measuring the distribution of an element between the mercury and aqueous phase as a function of applied voltage. The half-life of $255 \mathrm{No}$ is too short to allow time for the recovery of Ho from the $\mathrm{Hg}$ phase for assay, therefore Meyer et $a^{1}$ weasured the depletion of No in the aqueous phase as a function of a controlled potential. They assumed that equilibrium was reached in 3 minutes of electrolysis and that the electrode reaction was reversible. A sharp drop in No concentration in the aqueous phase occurred between -1.8 and $-1.9 \mathrm{~V}$ vs. the saturated calomel electrode or $-1.6 \mathrm{~V}$ vs. the standard hydrogen electrode. Ihus, their best estimates are sumiarized in the following equation.

$$
\mathrm{NO}^{2+}+2 \mathrm{e}^{-}=\mathrm{No}(\mathrm{Hg}) ; \quad E \mathrm{O}=-7.6 \pm 0.1 \mathrm{~V}
$$

If this potential is reduced by about the $0.9 \mathrm{~V}$ estimated for the amalgamation potential, then a value of about $-2.5 \mathrm{~V}$ would be given for the $I I \rightarrow 0$ couple.

\section{LAWRENCIUN}

Element 103, lak:encium, is the last member of the actinide series and its chemical nature shouid be similar to its counterpart in the lanthanide series, Lu. However, confirming experimental information is nearly nonexistent because of the $35-s$ half-life of $256 \mathrm{Lr}$ and the great difficulty in producing d useful quantity for experiments. The bombardment of $249 \mathrm{cf}$ with $l_{B}$ ions is probably the most favorable nuclear reaction for producing $256_{L}$. Even so, only about ten atons have been made in each short irradiation and of these, only one or two were detected after completion of the chemical tests( $\underline{92})$.

Lawrencium was expected to have a $5 f^{14} 6 \mathrm{~d}^{2} \mathrm{~s}^{2}$ electronic configuration(93) although Brewer computed a $5 f^{14} 7_{5}^{2} 7 p$ configuration(5). Brewer's estimates have now been confimed by inulticonfigurational (rêlativistic) Dirac-Fock calculations in which the ground state of lawrencium was found to be a ${ }^{2} p_{1}$ or $7 s^{2} 7 p$ electronic configuration(94). This deviation from the $6 \mathrm{~d} 7 \mathrm{~s}^{2}$ configuration expected from extrapolation of the Periodic Table is due entirely to 
strong relativistic effects on the outermost $7 \mathrm{p} 1 / 2$ orbital. The energy difference between the two possible ground states is no fire than a few thousand wave numbers.

The ionization of $L r$ would be expected to stop with the $f^{14}$ core intact because of the enhanced binding energy of possible valence electrons in the filled $f$ shell. The stable valence state of $L r$ would then be the (III) state. Experiments to confim this oxidation state of $L r$ were undertaken by Silva and co-workers(92). They compared the extraction behavior of $L r$ with several tri- and tetravalent actinides and with $\mathrm{Ba}^{2+}, \mathrm{Ra}^{2+}$, and $\mathrm{HO}^{2+}$. A chelating extractant, thenoyltrifluoroacetone dissolved in methyl isobuty) ketone, was enployed to extract the tracer ions from aqueous solutions that had been buffered with acetate anions. Their results, shown in Fig. 13, denonstrate that $L r$ is extracted within the same $\mathrm{pH}$ range as the trivalent actinides and, therefore, prove that $L r$ is trivalent.

Further studies oi L $r$ have not been attempted.

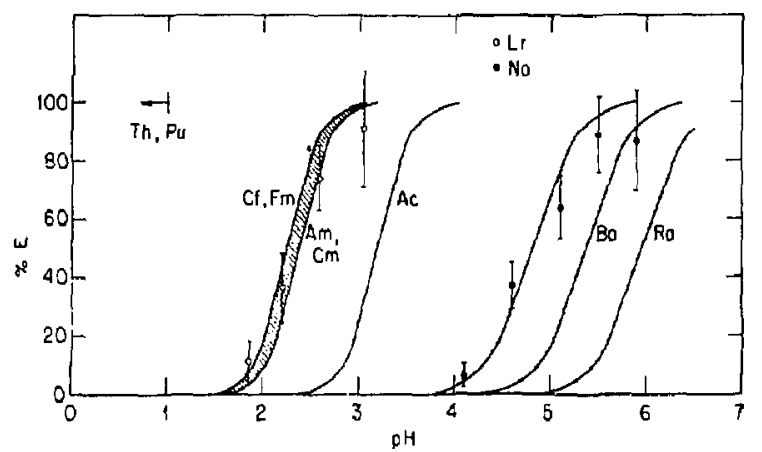

Fig. 13. Percent extracted into the organic phase as a function of the $\mathrm{pH}$ of the aqueous phase. Solid lines are a summory of earlier data by the same authors. Reprinted with the pemission of Pergamon Press (Ref. 92).

\section{ACTINIDE SUMMARY}

The main result ensuing from about 14 years of intensive study of the heavier actinides is the finding of an unexpected stability of the divalent state, Table 9, summarizing the redox properties of these elenents, most clearly shows the increasing stability of this state with increasing atomic number. The sinking of the $5 \mathrm{f}$ levels with respect to the Fermi level provides the explanation for this behavior. Thus, we see, as is also the case in the light actinides, another major differentiation between the $5 f$ actinide and $4 f$ lanthanide series of elentents. 
TABLE 9 Reduction Potentials of the Heavier Actinides. Reported as $-E^{\circ}$ vs Standard $H^{+}$Electrode

\begin{tabular}{|c|c|c|c|c|c|}
\hline Half Reaction & Es & $F \pi$ & Hd & No & $\underline{L r}$ \\
\hline $\begin{array}{r}I I-\amalg \\
I I \rightarrow 0 \\
I I I \rightarrow 0\end{array}$ & $\begin{array}{l}1.55 \\
2.20 \\
1.98\end{array}$ & $\begin{array}{l}1.75 \\
2.37 \\
1.95\end{array}$ & $\begin{array}{l}0.2 \\
2.4 \\
1.7\end{array}$ & $\begin{array}{c}-1.4 \\
2.5 \\
1.18\end{array}$ & $\frac{-}{2.05}$ \\
\hline
\end{tabular}

\section{TRANSACTINIDES}

Four elements are known with atomic numbers greater than that of lawrencium. Because none of the names proposed for these elements have received official acceptance from the International Union of Pure and Applied Chemistry, they are referred to as el ements 104, 105, 105, and 107, or E-104, etc. This lack of authorized names is very likely to continue for many more years because of difficulties in resolving conflicting claims for their discovery. A dimension of these conflicts, namely, the certitude of the atomic number assigned to a particular nuclide used in several of the chemical investigations, is not examined in this review.

The chemistry of these elements, as estimated from extrapolation of the Periodic Table and verified by quantum mechanical calculations, should follow that of another d transition series, comparable with the 5d series beginning with $H f$. Therefore, the chemical properties of E-l04 should be quite similar to those of Hf, and E-I05 to those of $\mathrm{Ta}_{3}$ and so forth. In aqueous solutions, E-104 would be expected to possess a stable tetravalent state while E-105 would be pentavalent. It is the verification of these predicted chemical properties that has been the main thrust of the experimental work with these el enents.

\section{Element 104}

The chemistry of E-104 has been investigated in the gas phase as the tetrachloride(95-98) and in aqueous solution as complexes of chloride(99) and a-hydroxyisobutyrate anions(100). It has been very much of an uphill struggle to produce and identify the few atoms used in these experiments and to perforil the experiments many times over with very short-lived isotopes. In the themo-chromatography research carried out at the Joint Institute for Nuclear Research Dubna, USSR, a 3-s isotope, 259104 , was produced by $22 \mathrm{Ne}$ bonbardment of 242pu targets. The aqueous chemistry was carried out with 1min 261104 fomed in the reaction of $248 \mathrm{Cm}$ with $18_{0}$ ions. Very few atoms were produced and identified in any of the E-104 chenical investigations.

The goal of the gab-piase experiments was to show the sharp difference in volatility of the higher halides of eka-Hf relative to the volatility of the preceeding Group IIIB series of actinides(95-97). The Group IVB tetrachlorides sublime at teaperatures slightly over $300^{\circ} \mathrm{C}$, whereas the actinide trichlorides would require temperatures three to four times greater before they became volatile at an atmosphere of pressure. Therefore, the volatility of E-104Cl 4 would be a distinctive measure of whether or not this element was eka-Hf. All such experiments were performed on-line at the Dubna accelerator. Atoms of E-104 recoiling from the target were stopped in a heated 
stream of inert carrier gas of $\mathrm{N}$ and then chorinated downstream with $\mathrm{TiCl}_{4}$ or mixtures of $\mathrm{SOCl}_{2}, \mathrm{NbCl}_{5}, \mathrm{ZrCl}_{4}$, and $\mathrm{TiCl}_{4}$. The molecules of $\mathrm{E}-\mathrm{IOACl}_{4}$ passed through a chromatographic column heated to $300-350^{\circ} \mathrm{C}$ and eventualiy deposited on mica detectors located inside and along the length of a section of the column held at $280^{\circ} \mathrm{C}$. Hundreds of hours of accelerator bean time resulted in the detection of 79 spontaneaus fission events, at first attributed to the decay of $0.3-5260104\{97)$. However, current work supports a halfiife of only $20 \mathrm{~ms}$ for this isotope $(101)$.

In the last vapour-phase experiments performed by Zvard's group(98), frontal chromatography of the chlorides was used to separate 3-5 259104 and coproduced $170,17 l_{H F}$ from $S C, 242 \mathrm{Cm}, 246 \mathrm{Cf}$, and $242 \mathrm{pu}$ also swept into the gas stream from the target region. The apparatus employed in this work was essentially unchanged from earlier experiments except that a thermal gradient was maintained beginning with $400^{\circ} \mathrm{C}$ at the entrance and decreasing to $50^{\circ} \mathrm{C}$ at the exit of the $70-\mathrm{cm}$ long thermo-chromatographic section. The Hf isotopes and 15 spontaneous-fission events were found deposited in this section of the themal-gradient column at a position corresponding to a condensation temperature of $220^{\circ} \mathrm{C}$. Scandi un and various actinide nuclides produced by other nuclear reaction with the target were found 100 to $125 \mathrm{~cm}$ upstream in an initial section of a $400^{\circ} \mathrm{C}$ tube. The yolatility of $104 \mathrm{Cl}_{4}$ clearly corresponded to that of $\mathrm{HfCl}_{4}$ and established $\mathrm{E}-\mathrm{jO4}$ as being eka-Hf.

During several hundred experiments, Silva and coworkers $(100)$ investigated the complexing and cation-exchange behavior of $i-m i n 26 i 104$. Recoil atoms of E-104 were trapped in an $\mathrm{NH}_{4} \mathrm{Cl}$ layer sublimed onto Pt discs, dissoived with anmonium $a$-hydroxyisobutyrate and passed onto a column of heated cation resin. Because of the strong formation of neutral and anionic complexes by the tetravalent IVB elements, one would expect very little adsorption and retention by the cation resin in the column. Indeed, this was the outcome of the many experiments, although the decay of only 17 atoms was observed after elution from the resin column. The elution position was the same as $\mathrm{Hf}$ and $\mathrm{Zr}$, which were separately tested. Nobelium and other actinides were retained on the resin until over loo column-volumes of eluant had passed through the column.

In later experiments wich tested the chloride complexation of E-104(99), computer automation was used to perfom all chemical manipulatiuns rapidiy, to prepare a sources, and to do a spectroscopy. An extraction chromatographic method was chosen to investigate chloride complexing in high concertrations of $\mathrm{HCl}$ which thereby avoided the hydrolysis reaction possible at lower acidities. The extraction columns were loaded with $0.25 \mathrm{~F}$ triocty?methylamionium chloride, since anionic-chloride complexes formed in the aqueous phase are strongly extracted by this amanium compound. Such cortplexes are formed in $12 \mathrm{M} \mathrm{HCl}$ by the Group IVB elements and are extracted, whereas Group IA, IIA, and IIIB elenents, including the actinides, form weaker complexes and are not appreciably extracted. Thus, these latter recoil products were eluted with $12 \mathrm{M} \mathrm{HCl}$ wile $2 \mathrm{r}$, Hf, and E-104 were extracted and subsequentiy eluted with $6 \mathrm{H} \mathrm{HCO}$, in wich anionic chloride complexation is less favored. Figure 14 shows the atoms of 261104 observed by $a$ decay in three sequential elution fractions. Only six events were observed in over one hundred experiments; one in fraction (a), two in fraction (b), and three in fraction (c). The percentage of Hf corresponding to these same fractions was $12 \%, 59 \%$, and $29 \%$. These results showed the chloride complexa$t$ ion of E-104 is cansiderably stranger than that of the trivalent actinides and is similar to that of $\mathrm{HF}$. 


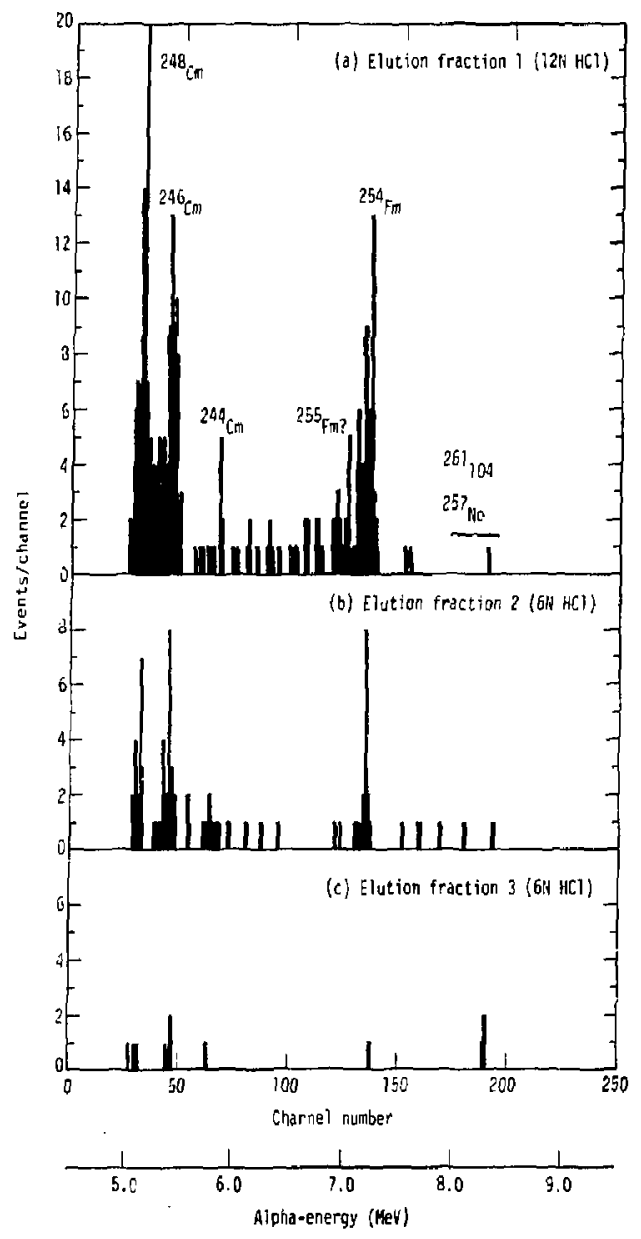

Fig. 14. Alpha spectra showing the decay of a few 261 y04 atoms in three, sequential elution fractions from a colurn containing an anionic extractant (see text). Reprinted with the pemission of Pergamon Press (Ref. 99). 


\section{Element 105}

Our chenical knowledge of the heavy elements ends with $E-105$ although the nuclear properties are known for several isotopes of elements 106 and 107. Element 105, with a $6 \mathrm{~d}^{3}$ electronic configuration, is expected to have the general chemical properties of its $5 d^{3}$ homolog, Ta. Zvara et al., using much of the same themochromatographic techniques amployed eartier in their studies of element 104, have extended the method to detemining the volatilities of the chloride and bromide conpounds of E-105(102,103). The chloride of E-105 was deprsited on the walls of the chronatography tube at $\sim 150^{\circ} \mathrm{C}$ but because of the short $2-5$ half. lower in temperature was suggested by the authors. This correction was based on the appreciable decay of the 26105 nuclei during their travel through the tube. The corrected distribution of the 18 observed spontaneous fisston events indicated that the chlorides of $E-105$ are more volatile than $\mathrm{Hf}$ and less volatile than $\mathrm{Nb}, \mathrm{d} \mathrm{dd}^{3}$ homolog of $\mathrm{E}-105$.

The bromides of E-105 were also found to be very volatile as shown by the location of the circles in relation to the thernal gradient in the upper part of Fig. 15. Niobium, which in separate experiments was shown to have the same deposition temperature as $\mathrm{Ta}$, is obviously more volatile than $\mathrm{E}-105$. From this work, the boiling point of E-105Brs was estimated to be $430^{\circ} \mathrm{C}$. An analysis of the boiling points of pentabromides of the same structure allowed an estimate of $\sim 0.09 \mathrm{~nm}$ for the metallic radius, or $\sim 0.02 \mathrm{~nm}$ larger than that of $\mathrm{Nb}$ and $\mathrm{Ia}$. In sum, all of the experimental observations are consistent with E-lo5 being a homolog of $\mathrm{Nb}$ and $\mathrm{Ta}$.
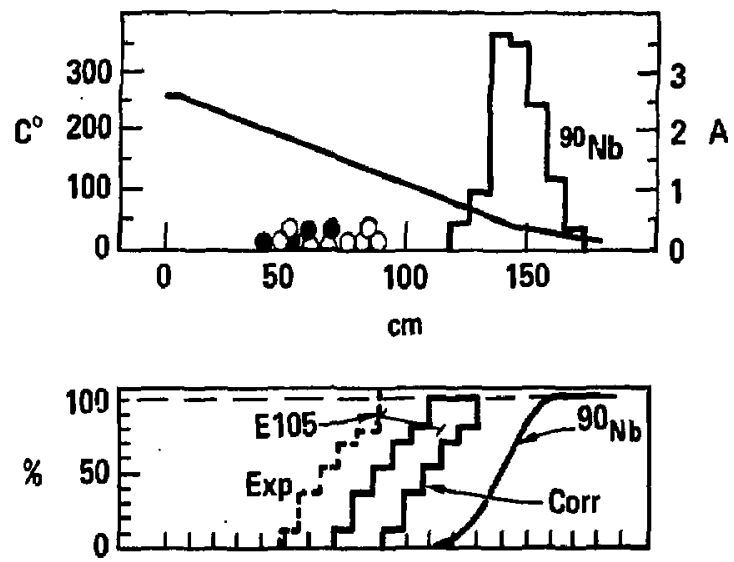

Fig. 15. Upper: Thermal gradient and deposition positions of E-105 (circles) and No (histogran) bromides.

Lower: integral distributions of experimental (dashed lines), and corrected (solid area) of E-105 and of $\mathrm{Nb}$ (solid curve) bromides. Redrawn from Ref. 103. 


\section{ACKNOWLEDMENT}

This review was prepared under the auspices of the U.S. Department of Energy by the Lawrence Livermore National Laboratory under contract number W-7405ENG-48.

\section{REFERENCES}

1. Ferguson, D. E. (1978). Proceedings Commemorating the 25th Anniversary of Elements 99 and 100 , Seaborg, G. T., ed. L LBL 7701 Report, National Tecnical Information Service, Springville, Virginia, p. 35.

2. Gutmacher, R. G., Evans, J. E., and Hulet, E. K. (1967). J. Opt. Soc. Am. 57, 1389.

3. Comway, J. G. (1978). In Ref. 1, p. 69.

4. Worden, E. F., Lougheed, R. H., Gutmacher, R. G. and Conway, J. G. (1974). J. Opt. Soc. Am. 64, 77.

5. Brewer, L. (1971). J. Opt. SOC. AA. 61, 1101.

6. Brewer, L. (1971). J. Opt. Soc. Am. 61, 1666.

7. Sugar, J. (1974). J. Chern. Phys. 60, 4103.

B. Rajnak, K. and Shore, B. W. (1978). J. Opt. Soc. Am. $68,360$.

9. Goodman, L. S., Diamond, H., and Stanton, H. E. (1975). Phys. Rev. A 11, 499 .

10. Dittner, P. F. and Bemis, C. E., Jr. (1972). Phys. Rev. A 5, 481.

11. Haire, R. G. and Baybarz, R. D. (1979). J. Phys. Collo. (Orsay) 49, C4-101.

12. Hübener, 5. (1980). Radjochem. Radioanal. Lett. 44, 79.

13. Nugent, L. J., Burnett, J. L., and Morss, L. R. (1973). J. Chem. Thermody. 5, 665.

14. Hard, J. W., Kleindschmidt, P. D., Haire, R. G., and Brown, D. (1980). Lanthanide and Actinide Chomistry and Spectroscopy, Edelstein, N., ed., American Chemical Society Symposium Series T3t, Washington, p. 199.

15. Ho, Powell, and Lilly (1972). J. Phys. Chem. Ref. Data 1, 418.

16. Edelstein, N. (1971). J. Chem. Phys, 54, 248B,

17. Boatner, L. A., Reynolds, R. W., Finch, C. B., and Abraham, M. M. (1975). Phys. Rev. B, 13, 953.

18. Bouissières, G., Jouniaux, B., Legoux, Y., Merinis, J., David, F., and Samhoun, K. (1980). Radiochem. Radioanal. Lett. 45, 121. 
19. Yarga, L. P., Baybarz, R. D., Reisfeld, H. J., and Asprey, L. 8. (1973). J. Inorg. Nucl. Chem. 35, 2775.

20. Nugent, L. J., Baybarz, R. D., Burnett, J. L., and Ryan, J. L. (1971). J. Inorg. Nucl. Chem. 33, 2503.

21. Lebedev, I. A. (1978). Soviet Radiochemistry 20, 556.

22. Haire, R. G. and Baybarz, R. D. (1973). J. Inorg. Hucl. Chem. 35, 489.

23. Peterson, J. R. (1978). In Ref. 1, p. 55.

24. Fujita, D. K., Cunningham, B. B., and Parsons, T. C. (1969), Inorg. Nucl. Chem. Lett. 5, 307.

25. Peterson, J. R., Ensor, D. D., Fellows, R. L., Haire, R. G., and Young, J. P. $(1979)$. J. Phys. Collo. (Orsay) 49. C4-111.

26. Fellows, R. L., Peterson, J. R., Young, J. P. and Haire, R. G. (1977). The Rare Earths in Modern Science and Technology, McCarthy, G. J. and Ryyne, J. J., ed., Plenum Press, Hew York, j. 493.

27. Fellows, R. L., Peterson, J. R., Hoe, M., Young, J. P., and Haire, R. G. (1975). Inorg. Nucl. Chem. Lett. 11, 737.

28. Fellows, R. L., Young, J. P., Haire, R. G., and Peterson, J. R. (1978). in Ref. I and private communication.

29. Hulet, E. K. and Bodé, O. D. (1972). MTP International Review of Science, Series I, Vol, 7, Lanthanides and Actinides, Bagnall, K. W., ed., Butterworths, London, p. T.

30. Kosyakov, V. N. Chudinov, É. G., and Shretsov, I. K. (1974), Soviet Radiochemistry 16, 722.

31. Street, K., Jr. and Seaborg, G. T. (1950). J. Am. Chem. Soc. 72, 2790.

32. Hulet, E. K., Gutmacher, R. G., and Coops, M. S. (1961). J. Inorg. Nucl. Chem. 17, 350 .

33. Choppin, G. R. and Silya, R. J. (1956). J. Inorg. Nucl. Chem. 3, 153.

34. Campbel1, D. 0. (1970). Ind. Eng. Chem. Process Des. Develop. 9, 95.

35. Harbour, R. M. (1972). J. Inorg. Nucl. Chem. 34, 2680.

36. Fujita, D. K., Cunningham, B. B., Parsons, T, C, and Peterson, J. R. (1969). Inorg. Nucl. Chem. Lett. 5, 245.

37. Hugent, L. J., Baybarz, R. O., Herner, G. K., and Friedman, H. A. (1970). Chem. Phys. Lett. 7, 179.

38. Varga, L. P., Baybarz, R. D., Reisfeld, M. J., and Mann, J. B. (1973). J. Inorg. Nucl. Chem, 35, 2303.

39. Carnall, H. T., Cohen, D., fieids, P. R., Sjoblom, R. K., and Barnes, R. F. (1973). J. Chen, Phys, 59, 1785. 
40. Nugent, L. J., Burnett, J. L., Baybarz, R. D., Herner, G. K., Tanner, S. R., Tarrant, J. B., and Keller, O. L., Jr. (1969). J. Phys. Chem. 73, 1540 .

41. Harnon, H. D. and Peterson, J. R. (1972). Inorg. Nucl. Chenr. Lett. 8, 57.

42. Hussonnois, M., Hubert, S., Brillard, L., and Guillaumont, R. (1973). Radiochem. Radioanal. Lett. 15, 47.

43. McDowell, W. J., and Coleman, C. F. (1972). J. Inorg. Nucl. Chem. $34,2837$.

44. Harmon, H. D. and Peterson, J. R. (1972), J. Inorg. Nucl. Chem, 34, 1381.

45. Hubert, S., Hussonnois, M., Brillard, L., Goby, G., and Guillaumont, R. (1974). J. Inorg. Nuc). Chen. 35, 2366.

46. Aly, H. F, and 'atimer, R. M. (1970). Radiochim, Acta. 14, 27.

47. Myasoedov, 8. F., Guseva, L. I., Milyukova, M. S., and Chmutova, M. K. (1974). Analytical Chemistry of the Transplutenium Elements, Kester Publishing House, Jerusalem, p. 358.

48. Lundqvist, R. D., Hulet, E. K., Baisden, P. A. (1979). to be published.

49. Chudinov, E. G. and Pirazhkov, S. V. (1973). Soviet Radiochemistry 15, 200 .

50. David, F., Samhoun, K., Guillaumont, R., and Edelstein, N. (1978). J.Inorg. Nucl. Chem. 40, 69.

52. Nugent, L. J. (1975). J. Inorg. Nucl. Chem. 37, 1767.

53. Samhoun, K. and David, F. (1979). J. Inorg. Nucl. Chem. 41, 357.

55. Nuggent, L. J. (1969). J. Phys. Chem. 73, 1177.

56. Duykaerts, G. and Gilbert, B. (1977). Inorg. Hucl. Chem. Lett. 13, 537.

57. Mikheev, N. B, Spitsyn, V. I., Kamenskaya, A. N., Rozenkevich, N. A., Rumer, I. A., and Auérman, L. N. (1972). Soviet Radiochemistry 14, 494.

58. Mikheev, N. B. and Rumer, I. A. (1972). Soviet Radiochemistry 14, 502 ,

59. Ionova, G. V., Mikheev, H. B., and Spitsyn, V. I. (1978). Soviet Radiochemistry 20, 89 .

60. Borg, R. J. and Dienes, G. J. (1981). J. Inorg. Nucl. Chem. 43, 1129.

61. Coodman, L. S., Diamond; H., Stanton, H. E., and Fred, M. S. (1971). Phys. Rev. A 4, 473.

62. Porter, F. T., and Freedman, M. S. (1971). Phys. Rev. Lett. 27, 293. 
63. Porter, F. T., and Freedman, M. S. (1978). J. Phys. Chem. Ref. Oata ?, 1267.

64. Fricke, B., Desclaux, J.-P., and Waber, J. T. (1972). Phys. Rev. Lett. 28, 714 .

65. Zvara, I, Belov, V. Z., Domanov, V. P., Zhookov, B. L., Ryotts, T., Chubener, Z., Shalaeuski, M. R. (1976). Joint institute for Muclear Research, Dubna, USSR, Preprint P6-10334 (in Russian).

66. Merinis, J., Legoux, Y., and Boutissières, G. (1973). Radchem. Radioanal. Lett. 13, 221.

67. Choppin. G. R., Harvey, B. G., and Thompson, S. G. (1955). J. Inorg. Nucl. Chem. 2, 66

68. Horwitz, E. P. and Bloomquist, C. A. A. (1973). J. Inorg. Nucl. Chem. 35,271 .

69. Horowitz, E. P. and Bloomyuist, C. A. A. (1969). Inorg. Nuc7. Chem Lett. 5,753 .

70. Hubert, S., Hussonnois, M., Brillard, L., Gody, G. and Guillaumont, R. (1974). J. Inorg. Nucl. Chem. 36, 2361.

71. Hubert, S., Hussonnois, M., Brillard, L., Guillaumont, R. (1976). Iransplutonium Elements, W. Mull ler and R. Lindner, Eds., North-Holland, Amsterợm, p. 10́g.

72. Hussonnois, M., Hubert, S., Aubin, L., Guillaumont, R., Boussieres, G. (1972). Radchem. Radioanal. Lett. 10, 231.

73. Mikheer, N. B., Spitsyn, V. 1., Kamenskaya, A. N., Grozdev, B. A., Druin, V. A., Rumer, I. A., Dyachkova, R. A., Rozenkevitch, N. A., Auérman, L. N. (1972). Inorg. Nucl. Chem. Lett. 8, 929.

74. Rozenkevich, N. A., Mikheev, N. B., Rumer, I, A., Auérman, L. N., Gvozdev, B. A., Kamenskaya, A. N. (1975). Radioknimiya 17, 441,

75. Mikheev, N. B., Spitsyn, V. I., Kamenskaya, A. N., Konovalova, N. A., Rumer, 1. A., Auérman, L. M., Podorozhnyi, A. M. (1977). Inorg. Nuc). Cher. Lett. 13, 651 .

76. Rumer, 1. A., Mikheev, H. B., Kanenskaya, A. H., Konoyalova, M. A., Auéman, L. H., and Podorozhnyi, A. H. (1979). Soviet Radiochemistry $21,232$.

77. Hulet, E. K., Lougheed, R. W., Baisden, P. A., Landrum, J. H., Wild, J. $F_{1}$, and Lundquist, R. F. D. (1979). J. Inorg. Nucl. Chen. 41, 1743.

78. Samhoun K. and David F. (1976). Transplutonium Elements, Muiller W. and Lindner, R., Eds., North-Holland, Aimsterdam, p. 297.

79. David F., Samhoun, $X_{1}$, Hulet, E. K., Baisden, P. A., Dougan, R., Landrum, J. H., Lougheed, R. W., Wild, J. F., and O'Kelley, G. D. (1981). J. lnorg. Nucl. Chemo (in press). 
80. Hulet, E. K., Lougheed, R. W., Brady, J. D., Stone, R. t., and Coops, M. S. (1967). Science 158, 486.

81. Mály, J. and Cunningham, B. 8. \{1967\}. J. [norg. Nucl. Chen. Lett. 3, 445.

B2. Mály. J. (1969). J. Inorg. Nucl. Chem. 31, 741.

83. Sanhoun, K., David, F., Hahn, R. L., O'Kelley, G. D., Tarrant, J. R., and Hobart, 0. E., (1979). J. Inorg. Nucl. Chem. 41, 1749.

84. Hikheev, N. 8., Spitsyn, V. 1., Kamenskaya, A. N., Rumer, I. A., Grozder, B. A., Rosenkevich, N. A., and Auśman, L. N. (1973). Doki.' Akad. Nauk SSSR 208, 1146.

85. Mikneev, N. B., Spitsyn, V. 1., Kamenskaya, A. N., Mikulski, J., and Petryna, T. (1980). Radiochen. Radioana). Lett. 43, 85.

86. Mály, J., Sikkeland, T., Silva, R., and Ghiorso, A. (1968). Science $160,1114$.

87. Silva, R. J., McDowell, K. J., keller, 0. L., Jr., and Tarrant, J. R. (1974). Inorg. Chem. 13, 2233.

88. Silva, R. J., Sikkeland, T., Nurnid, M., Ghiorso, A., and Hulet, E. K. (1969). J. Inorg. Nucl. Chem. 31, 3405.

89. McDowell, H. J., Keller, 0. L., Jr., Dittner, P. E., Tarrant, J. R., and Case, G. N. (1976). J. Inorg. Kucl. Chen. 38, 1207.

90. Beck, H. P., and Bärnighausen. H. (1971). 2. Anorg. Allg. Chem. 386, 221 .

9i. Meyer, R. E., McDowell, W. J., Dittner, P. F., Silva, R. J., and Tarrant, J. R. (1976). J. incrg. Nucl, Chem. 38, 1171.

92. Silva, R., Sikkeland, I., Murmia, M., and Ghiorso, A. (1970), Inorg. Nucl. Chen. Lett. 6, 733.

43. Nugent, 1. J., Vander Slusis, .. 1., Fricke, B., and Mann, J. B. (1974). Phys. Rev. A 9, 2270 .

94. Desclaux, J.-P. and Fricke, 8. (1980). J. Phys. 41, 943.

95. Zvara, 1., Chuburkor, Yu. T., Tsaletka, R., and Shalagyskii, M. R. (1969). Soviet Radiochemistry 11, 153.

96. Zvara, I., Chuburkov, Yu. T., Tsaletka, R., and Shalaevskii, M. R. (1969). Soviet Radiochemistry 11, 161.

97. Zvara, I., Chuburkov, Yu. T., Belov, V. Z., Buklanov, G. V., Zakhvataev, B. B., Zvarova, T. S., Maslov, O. D., Caletka, R., and Shalaevski i, M. R. (1970). J. Inorg. Nucl. Chem. 32, 1885.

98. Zvara, I., Belov, V. Z., Chelnokov, L. P., Domanov, Y. P., Hussonois, M., Korotkin, Yu. S., Schegolev, Y. A., and Schalaevskij, M. R. (1971). Inorg. Nucl. Chem. Lett. 7, 1109. 
99. Hulet, E. K., Lougheed, R. W., Wild, J. F., Landrum, J. H., Nitschke, J. M., and Ghiorso, A. (1980). J. Inorg. Nucl. Chen. 42, 79.

100. Silya, R., Harris, J., Nurmia, M., Eskola, K., and thiorso, A. (1970). Inorg. Nucl. Chem. Lett. 6, 871 .

107. Nitschke, J. M., Fowler, M., Ghiorso, A., Leber, R. E., Nurnia, M., Somerville, L. P.. Killiams, K. E., Hulet, E. K., Landrum, J. H., Lougheed, R. W., Wild, J. F., Bemis, C. E., Silva, R. J., and Eskola, P. (1981). Nuci. Phys. A 352, 138.

102. Zvara, I. (1973). XXIV International Congress of Pure and Applied Chemistry, Butterworths, London, 1974, vol. 6, p. 73 .

103. Zuara, I., Belov, V. Z., Domanov, V. P., and Shaldevskii, M. R. (1976). Soviet Radiochemistry 18,328 .

\author{
IMSC I.AIMEK
}

This documum was prepared as an account of work somenored hy an agency of

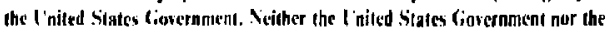
I nisersily of C Glifornia not any of their comployers, makes any harranty. ct. press or implied, ir assumus any legal liability or responsisisility for the accuracy, snmpletenews, or usefulness of any information, apparatus, priduct, or

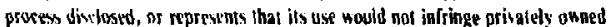
rights. Reference herein to any specific commercial pruducts, process, or sers tice by Irade name, trademark, manufuciurer, or otherwise, does nol necessarily constitute or imply its endorectent, recommendation, or las oring by lhe linited Stutes fiovernment or the t niversity of California. The vinws and opiniuns of suthoss expressed threin do not secessarily state or ieflect those of the I nited Siates fiovernment theteof, and shall not be used for advertising or product en. dorstmerul purposes. 